\title{
Recent Warming in the Western North Pacific in Relation to Rapid Changes in the Atmospheric Circulation of the Siberian High and Aleutian Low Systems*
}

\author{
YOUNG-HYANG PARK \\ LOCEAN/DMPA, Muséum National d'Histoire Naturelle, Paris, France \\ JONG-HWAN YOON \\ Research Institute for Applied Mechanics, Kyushu University, Fukuoka, Japan \\ YONG-HOON YOUN \\ Korean Academy of Meteorology and Climate, Seoul, South Korea \\ FRÉDÉRIC VIVIER \\ CNRS, LOCEAN/IPSL, Université Pierre et Marie Curie, Paris, France
}

(Manuscript received 14 October 2010, in final form 9 September 2011)

\begin{abstract}
On the basis of a new East Asian winter monsoon (EAWM) index and by analyzing the relationship between sea surface temperature (SST) anomalies and different atmospheric and oceanic factors in winter, this study investigates the causes of the recent unusual warming in the western North Pacific Ocean. Analyses presented here emphasize the dual contribution from the atmosphere and ocean to the local SST variability, with the relative importance of each contributor varying with the period and place. During the period 1970-89, the EAWM, controlled mostly by the Siberian high, is predominantly responsible for the SST variability in most of the western North Pacific, whereas in the period 1990-2005 ocean dynamics become increasingly important in most places or even dominant in the Kuroshio-Oyasio Extension (KOE) region. The delayed response of the KOE SST to basinwide wind stress curl forcing via Rossby waves is epoch dependent and is significant at lags of 1,3, and $4 \mathrm{yr}$ before 1990 but only at $1 \mathrm{yr}$ afterward. This epoch dependency of the impact of Rossby waves is related to the different locations of the centers of action of wind stress curl in the midlatitude North Pacific between the two epochs. In addition, mean advection of the EAWM-driven anomalous SST from the southern East China Sea, which can be transported into the KOE region in about a year by the Kuroshio, likely affects the KOE SST lagged by 1 yr. The strongest positive SST trend observed in the western North Pacific results from the combined effects of the abrupt weakening of the EAWM due to the unprecedented decline of the Siberian high and the increasing role of the ocean. The latter is best evidenced by the 1-yr delayed response of the western North Pacific via the gyre circulation adjustment to the basinwide decadal-scale wind stress curl change associated with the northward shift of the strengthened Aleutian low.
\end{abstract}

\footnotetext{
* Supplemental information related to this paper is available at the Journals Online website: http://dx.doi.org/10.1175/2011JCLI4142.s1.
}

Corresponding author address: Young-Hyang Park, LOCEAN/ DMPA, Muséum National d'Histoire Naturelle, 43 rue Cuvier, 75005 Paris, France.

E-mail: yhpark@mnhn.fr

\section{Introduction}

Global SSTs have been rising since the late nineteenth century, with the most rapid warming having occurred during the 1980s and 1990s with an increase of $0.3^{\circ} \mathrm{C}$ from 1981 to 2005 for the ice-free global oceans $(\mathrm{Yu}$ and Weller 2007), yielding a global mean SST trend of $0.125^{\circ} \mathrm{C}$ ecade $^{-1}$. Despite this global upward trend, the 
(a) Annual SST Trends for 1981-2005

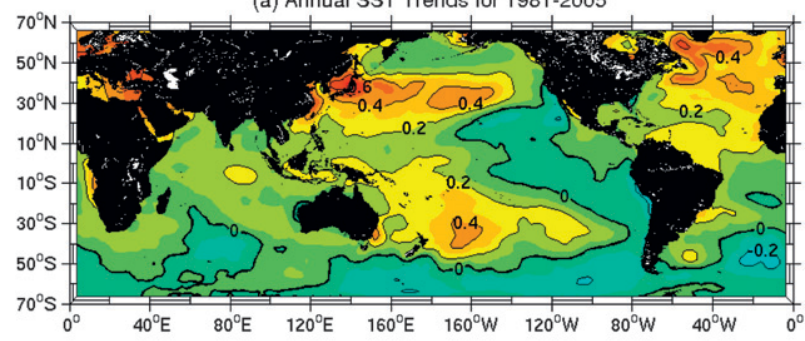

(b) NH Winter SST Trends for 1981-2005

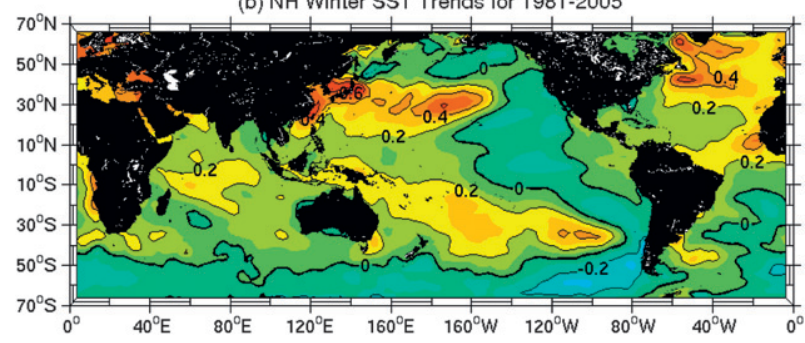

FIG. 1. Global map of SST trends for 1981-2005 from the ERSST dataset used in this paper. (a) Annual trends. (b) Winter (DJF) trends. Contours are every $0.2^{\circ} \mathrm{C}$ decade $^{-1}$ and the zero trend is shown by boldface lines.

sea surface warming is not geographically homogeneous but shows rather great regional differences, revealing even a slight cooling trend in most of the Southern Ocean south of $45^{\circ} \mathrm{S}$ and the eastern tropical Pacific (Fig. 1). The western boundary of the subtropical North Pacific Ocean, comprising the East Asian marginal seas as well as the Kuroshio-Oyashio Extension (KOE) region east of Japan, shows the greatest warming of all oceans (up to $0.87^{\circ} \mathrm{C}$ decade $^{-1}$ at $38^{\circ} \mathrm{N}, 142^{\circ} \mathrm{E}$ ). The spatial pattern is globally very similar between the annual (Fig. 1a) and winter (Fig. 1b) trends and there is no significant difference especially in the western boundary region close to the East Asian coast, suggesting that the impact of winter SST changes there persists and affects the local SST over the whole year. Also, as the spatial pattern of the SST trend is sensitive to the choice of the analysis period (e.g., Solomon et al. 2007), the strong local maximum in the western North Pacific seen in Fig. 1 is likely to be associated with the decadal variability as well as the long-term trend. As winter is the season when atmospheric forcing of the ocean is strongest and as there have been abrupt changes in the Siberian high and Aleutian low in the late 1980s, as will be seen later, we are particularly interested here in performing a systematic correlation analysis between the atmospheric circulation changes and SST anomalies in winter on interannual to decadal time scales and for two periods before and after 1990.

The Siberian high (SH) is the strongest cold-core high pressure system affecting the Northern Hemisphere in boreal winter, with its center being located in the northwestern Mongolia region southwest of Baikal Lake (Fig. 2; Gong and Ho 2002). As the prominent flow feature along the eastern flank of the anticyclonic $\mathrm{SH}$, the East Asian winter monsoon (EAWM) is characterized by prevailing northerlies blowing over eastern China, Korea, Japan, and the surrounding marginal seas. The easternmost branch of the monsoon flow, which is characterized by the 1016-hPa isobar of climatological winter sea level pressure (SLP) in Fig. 2, descends across the eastern side of the Japan/East Sea (JES) and bends sharply eastward after crossing Japan to extend beyond the date line at $25^{\circ} \mathrm{N}$, across which the zonal wind direction reverses from westerlies to the north to easterlies to the south. Located close to the eastern coast of the Eurasian continent, the western North Pacific is significantly affected by cold outbreaks from the East Asian continent, causing sharp temperature decreases and wind speed increases in a large area from East Asia to the western North Pacific (Chang et al. 2006).

There have been several attempts to relate the ocean variability of the western boundary region off the Asian coast to different climate indices, but the results are

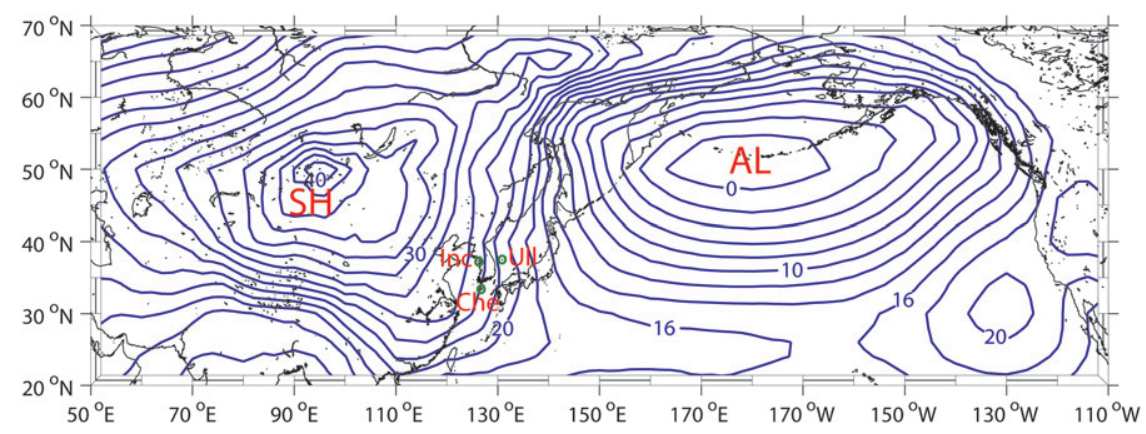

FIG. 2. Climatological map of winter (DJF) SLP showing the two dominant pressure systems over East Asia (Siberian high) and the northern North Pacific (Aleutian low). Contours are every $2 \mathrm{hPa}$ and a common value of $1000 \mathrm{hPa}$ has been subtracted from the original SLP at each data point, for the sake of convenience. 
often debated without always yielding a consistent view. Watanabe et al. (1987) reported that the interannual variations in water temperature along the coast of the JES are well correlated with the EAWM intensity, which is in line with Senjyu et al. (1999), who showed that the EAWM is the principal cause of the leading mode of interannual sea level variations along the entire coast of Japan. In contrast, Gordon and Giulivi (2004) claimed that the low-frequency variability of sea level and SST in the JES rather correlates with the Pacific decadal oscillation (PDO), whereas Park and Oh (2000) argued that the interannual variability of SST in the East Asian marginal seas including the Yellow Sea, JES, and East China Sea has significant coherence with the Niño-3.4 SST. Minobe et al. (2004) suggested that the decadal variability of the upper-layer temperature of the JES is primarily influenced by the $\mathrm{SH}$ and secondarily by the Aleutian low (AL).

In addition to changes in the surface atmospheric circulation, the importance of ocean heat transport for the SST variability in the western North Pacific has recently been emphasized. Based on a simple modeling study of the upper-ocean heat budget in the Kuroshio Extension region for the period of 1993-2000, Vivier et al. (2002) showed that while seasonal SST variations are mostly controlled by surface heat fluxes, ocean advection becomes as important as surface fluxes for the nonseasonal mixed layer temperature tendency (advection is however identified as the main contributor to changes in the nonseasonal heat content of the upper ocean). These results are in agreement with those of Qiu and Kelly (1993) and Qiu (2000). In particular, Kelly (2004) showed that for the extended period 1970-2000, the largest lateral fluxes occurred in the 1990s and the opposite ones in the 1970s, which might be related to decadal changes in the North Pacific subtropical gyre circulation caused by basin-scale changes in wind forcing. Indeed, Deser et al. (1999) previously suggested that the decadal change in geostrophic transport along the Kuroshio Extension is consistent with the change in Sverdrup transport inferred from the wind stress curl field, with the decadal-time-scale thermocline variation along the western boundary lagging $4-5 \mathrm{yr}$ relative to the basinwide wind stress curl. Similarly, Schneider and Miller (2001) and Seager et al. (2001) showed that the wintertime SST of the KOE region is strongly correlated with wind stress curl variations in the interior midlatitude North Pacific, but with a lag of several years due to the adjustment of the gyre circulation via baroclinic Rossby waves. Likewise, comparing altimeter sea surface height ( $\mathrm{SSH})$ and hindcasts from a simple linear vorticity model, Qiu (2003) and Qiu and Chen (2005) demonstrated that modulations in the strength of the
Kuroshio are caused by PDO-related wind stress curl variations in the eastern North Pacific, mediated by baroclinic Rossby waves.

It is clear from the above short review that interannual and decadal-time-scale SST anomalies in the western North Pacific are under great influence of concurrent and preceding changes in the atmospheric circulation of both the SH and AL systems as well as associated ocean circulation anomalies. While the influence of the respective atmospheric circulation change of either the $\mathrm{SH}$ or AL system on the regional SST variability has been addressed separately in previous works, a more complete study considering both atmospheric circulation systems together with ocean dynamics has not been undertaken. The purpose of the present paper is therefore to carry out such a study in a step-by-step manner.

\section{Data}

For describing the variability of the ocean and atmosphere at their interface, we analyzed two datasets of observation-derived SST and SLP. For the former dataset, we used version 2 of Smith and Reynolds's (2005) extended reconstruction SST (ERSST) analysis, for which monthly gridded $\left(2^{\circ} \times 2^{\circ}\right)$ global SST data are available online (http://www.ncdc.noaa.gov/pub/data/ ersst-v2/). For the latter dataset, we used the so-called Trenberth SLP dataset (Trenberth and Paolino 1980), which contains the monthly gridded $\left(5^{\circ} \times 5^{\circ}\right)$ SLP data covering the Northern Hemisphere from $15^{\circ} \mathrm{N}$ to the North Pole (http://dss.ucar.edu/datasets/ds010.1/). For the heat flux-SST relationship, we used the Objectively Analyzed Air-Sea Fluxes (OAFlux; Yu and Weller 2007) products available online (ftp://ftp.whoi.edu/pub/science/ oaflux/data_v3/monthly/turbulence/). We have also validated the turbulent fluxes from the National Centers for Environmental Prediction - National Center for Atmospheric Research (NCEP-NCAR) reanalysis (Kalnay et al. 1996; available online at http://dss.ucar.edu/datasets/ ds090.2). As for the ground-truth data, we used some available meteorological station data from the Korea Meteorological Administration (KMA), which include the Korea-mean monthly surface air temperatures averaged over seven selected stations (Lee 2009) and the monthly surface wind speeds at three selected island and coastal stations.

Monthly climate indices used here, such as the Arctic Oscillation (AO), western Pacific (WP) pattern, PDO, and Southern Oscillation (SO), are available from the Climate Prediction Center of the National Oceanic and Atmospheric Administration (NOAA) (ftp://ftp.cpc. ncep.noaa.gov/wd52dg/data/indices/tele_index.nh). Other indices representing the intensity of the EAWM, SH, 
and AL are defined in the appendix based on the Trenberth SLP dataset.

In this study we focus on the climate variability during boreal winter, which is defined as December-February (DJF) for atmospheric variables (winds, air temperature, heat flux), but as January-March (JFM) for SST, as the coldest SST appears generally a month after the peaks in atmospheric variables. Monthly anomalies of each variable are computed relative to its monthly mean of the 1970-89 base period, and our convention of year corresponds to that containing January; for example, DJF 2004/05 is shown as 2005.

\section{Respective impacts of the EAWM and PDO on the winter SST}

A number of different definitions of the EAWM index exist in the literature, several of which are reviewed in the appendix, where a new index is proposed. These indices are then critically validated against observationderived surface variables (wind speed, SST, Tair) over Korea and the surrounding marginal seas where the prevailing wintertime northerlies from Manchuria descend southward (see Fig. 2). Our new index $\left(E A W M_{\text {park }}\right)$, defined as the normalized SLP difference between two eastern centers (SH and JES) of the Eurasian pattern (Wallace and Gutzler 1981; Barnston and Livezey 1987), correlates best with wintertime surface variables (Table A1). This index will be referred to as EAWMI, for simplicity, because it is the unique EAWM index that will be considered hereafter. It is also shown that the observed abrupt decline of the EAWM in recent decades is due mostly to the concomitant weakening of the $\mathrm{SH}$, a predominant teleconnection center of the Eurasian pattern. This dramatic weakening of the SH in recent decades has been noticed by many authors (Gong and Ho 2002; Panagiotopoulos at al. 2005; Youn 2005), and seems to be unprecedented over the past four centuries (D'Arrigo et al. 2005). The exact cause of the recent decline of the SH is unknown; however, Hori and Ueda (2006), using nine coupled atmosphere-ocean general circulation models, suggested that global warming could be a major cause. On the other hand, Takaya and Nakamura (2005) suggested that the amplification of $\mathrm{SH}$ is often caused by continent blockings, and Wang et al. (2010) showed that the recent decline in the SH is closely related to the decline of blocking over the Ural Mountains region.

Before investigating EAWM-SST correlations, the relationship among different indices is first assessed (Table 1), which shows two distinct groups of indices having significant correlations within each group. The first group is composed of EAWMI, the SH index (SHI),
TABLE 1. Correlation coefficients for 1970-2005 among different climate indices discussed in the text. Significant correlations at the $95 \%$ significance level are marked in boldface. See the appendix for details on the calculation of the thresholds of the significance.

\begin{tabular}{lccccrr}
\hline \hline Climate indices & SH & WP & PDO & AL & AO & \multicolumn{1}{c}{ SO } \\
\hline EAWM & $\mathbf{0 . 9 5}$ & $\mathbf{- 0 . 6 2}$ & 0.09 & -0.06 & $-\mathbf{0 . 3 4}$ & 0.15 \\
SH & & $-\mathbf{0 . 5 4}$ & 0.05 & -0.00 & -0.27 & 0.08 \\
WP & & & 0.18 & -0.11 & 0.15 & $-\mathbf{0 . 3 4}$ \\
PDO & & & & $-\mathbf{0 . 7 6}$ & $-\mathbf{0 . 4 9}$ & $-\mathbf{0 . 5 6}$ \\
AL & & & & & $\mathbf{0 . 5 4}$ & $\mathbf{0 . 4 2}$ \\
AO & & & & & & 0.06 \\
\hline
\end{tabular}

and the WP index, with the strongest correlation $(r=$ 0.95 ) between EAWMI and SHI, while the second group contains the PDO, AL, and SO indices showing also a good correlation among them, with the highest correlation $(r=-0.76)$ between the PDO index (PDOI) and the AL index (ALI). Note that EAWMI and PDOI are not significantly correlated with each other $(r=0.09)$, although they have a marginal or moderate correlation with the AO index. Therefore, EAWMI and PDOI appear as two statistically independent indices that are most tightly associated with the two predominant winter SLP systems over East Asia and the North Pacific (i.e., the $\mathrm{SH}$ and $\mathrm{AL}$ ).

While the PDO is well known as the leading SST mode of the North Pacific north of $20^{\circ} \mathrm{N}$ (Mantua et al. 1997), the relationship between EAWMI and the winter SST field is less well studied. We present in Fig. 3 the correlation coefficients of the JFM SST anomalies with EAWMI (Fig. 3a) as compared with those with PDOI (Fig. 3b) for 1970-2005. Also shown is a map of optimal correlations using jointly both indices as well as a map of the relative contribution ratios of EAWMI, with the difference of which from 1 representing relative contribution ratios of PDOI. These ratios were calculated from a multivariate regression analysis (e.g., Emery and Thomson 1997), which can be modeled in our case as $Z=a X+b Y+\varepsilon$, where $Z, X$, and $Y$ represent symbolically the normalized anomaly time series of SST, EAWMI, and PDOI, respectively. Two regression coefficients, $a$ and $b$, can be easily determined by minimizing the square error $\varepsilon^{2}$, the classical least squares approach. The ratio of each coefficient to their sum, or the relative contribution ratio $a /(a+b)$ or $b /(a+b)$, is plotted for one parameter (EAWMI) in Fig. 3d, given the sum of the two ratios equals to 1 . The optimal correlation at each grid point (Fig. 3c) was calculated by correlating the original SST anomalies and those regressed with the above-determined $a$ and $b$.

The area under significant influence of the EAWM is clearly separated from that of the PDO, with the former occupying the southwestern corner of the study area 

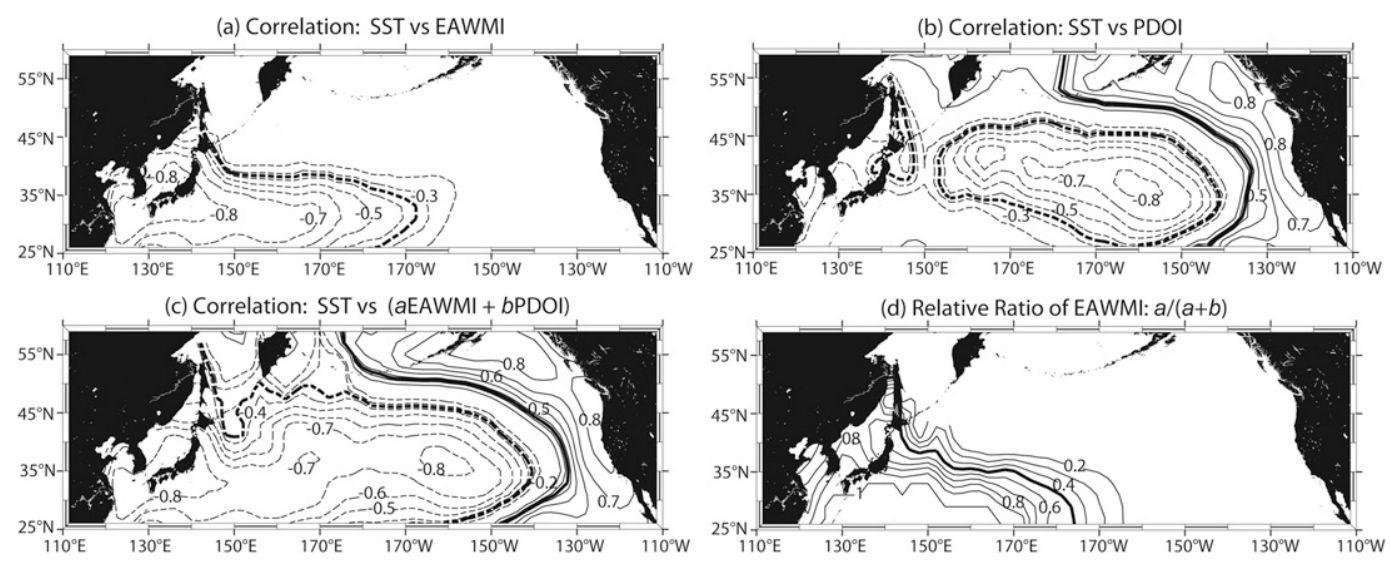

FIG. 3. Maps showing the correlation coefficients for 1970-2005 between JFM SST anomalies and (a) EAWMI, (b) PDOI, and (c) the regression with EAWMI and PDOI ( $a$ EAWMI $+b$ PDOI). Only absolute correlations $>0.2$ are shown, with the boundary of significant correlations at the $95 \%$ significance level being marked by boldface lines. (d) Relative contribution ratios of EAWMI, $a /(a+b)$, with the boundary of equal contribution $(50 \%)$ from both indices being marked by a boldface line. See the appendix for details on the calculation of the thresholds of the significance and the text for the multivariate regression analysis and relative contribution ratio.

including the marginal seas, the Kuroshio, its extension east of Japan, and the Kuroshio recirculation region southeast of Japan (Fig. 3a), while the latter occupies most of the remaining midlatitude North Pacific especially the central North Pacific and the eastern boundary region along the west coast of North America (Fig. 3b). As further convincing evidence of the preferential regional impacts of the two indices, Fig. 4 shows the normalized JFM SST anomalies averaged over the western boundary region $\left(30^{\circ}-40^{\circ} \mathrm{N}, 120^{\circ}-140^{\circ} \mathrm{E}\right)$ and the central North Pacific region $\left(35^{\circ}-45^{\circ} \mathrm{N}, 160^{\circ} \mathrm{E}-150^{\circ} \mathrm{W}\right)$ in comparison with anomalous time series of EAWMI and
PDOI, respectively. SST anomalies in these two regions show very dissimilar patterns, although they are well correlated separately with one of the two indices; in the western boundary region (Fig. 4a), the area-weighted SST anomalies strongly correlate with EAWMI at -0.79 but not with PDOI $(-0.18)$, which is completely reversed in the central North Pacific region (Fig. 4b), showing a highly significant (insignificant) correlation with PDOI (EAWMI) at $-0.67(-0.15)$. This means that the use of PDOI only may miss such an important area as the western boundary current region, but the combined use with EAWMI is indispensable for explaining more (a) -EAWMI (dotted) \& SST Ano (30-40N, 120-140E)

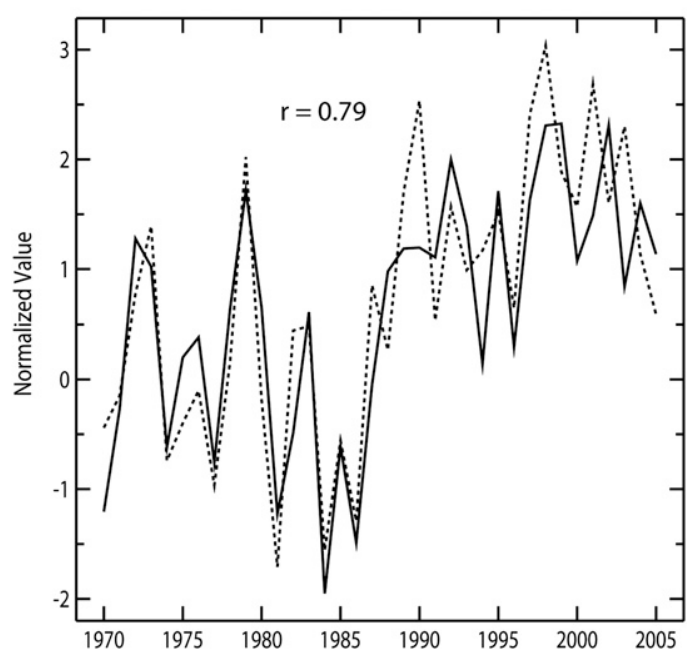

(b) -PDO (dotted) \& SST Ano (35-45N, 160E-150W)

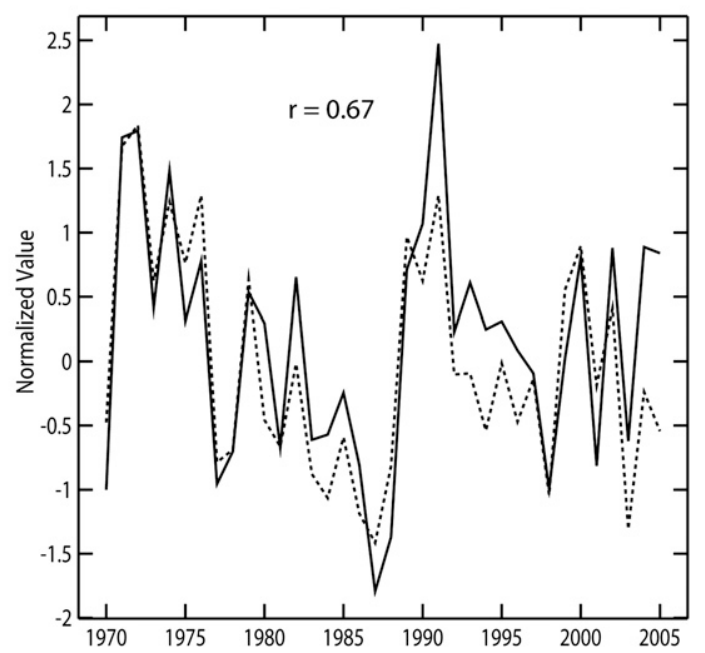

FIG. 4. (a) Normalized anomaly time series of the JFM SST anomalies (solid) averaged in the western boundary region $\left(30^{\circ}-40^{\circ} \mathrm{N}, 120^{\circ}-140^{\circ} \mathrm{E}\right)$ as compared with the negative EAWMI series (dotted). (b) As in (a), but for the central Pacific region $\left(35^{\circ}-45^{\circ} \mathrm{N}, 160^{\circ} \mathrm{E}-150^{\circ} \mathrm{W}\right)$ and PDOI. 
(a) WB Wind: NCEP (bl), OAFlux (r), Geostrophic (bk)

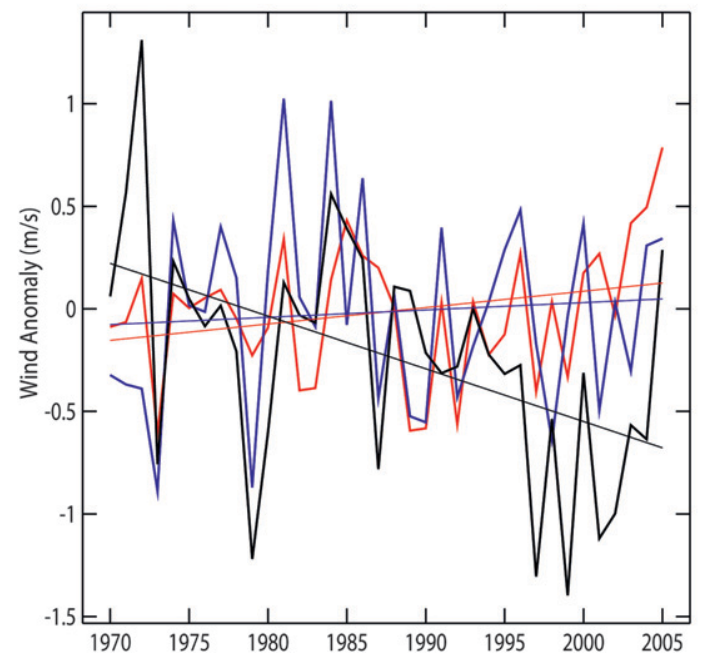

(b) Kuroshio-KOE Wind : NCEP (bl), OAFlux (r), Geostrophic (bk)

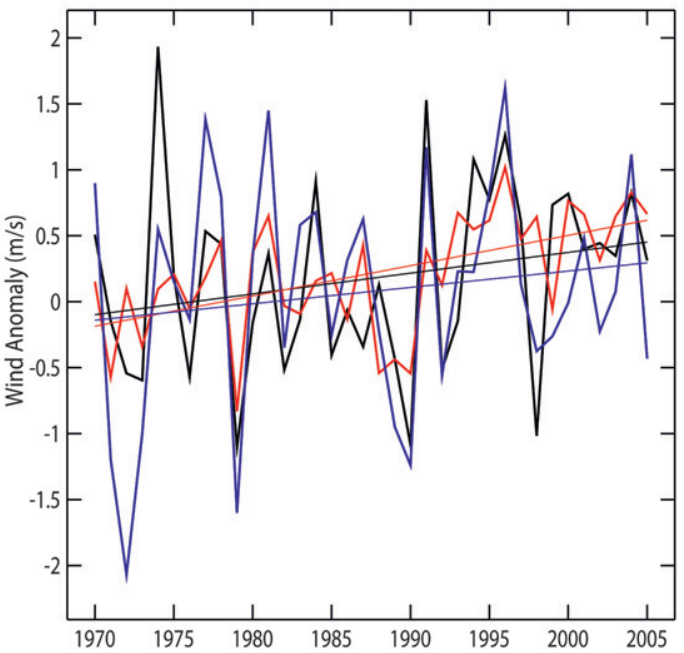

FIG. 5. Winter (DJF) wind speed anomalies from the NCEP-NCAR (blue), OAFlux (red), and Trenberth geostrophic wind (black) datasets averaged in (a) the western boundary region $\left(30^{\circ}-40^{\circ} \mathrm{N}, 120^{\circ}-135^{\circ} \mathrm{E}\right)$ and (b) the Kuroshio and $\mathrm{KOE}$ regions east of Japan $\left(30^{\circ}-40^{\circ} \mathrm{N}, 140^{\circ}-170^{\circ} \mathrm{E}\right)$.

completely the winter SST variability of the midlatitude North Pacific in its totality (Fig. 3c). Note that the recent greatest warming observed in the western North Pacific (see Fig. 1) largely coincides with the area strongly influenced by the EAWM variability, although it may not be a unique cause, as will be seen later.

\section{Relationship between turbulent heat flux and SST variations}

A first inference about the respective roles played by the atmosphere and the ocean for causing the SST variability can be made by a simple correlation method proposed by Cayan (1992). That is, negative correlations between the air-sea turbulent heat flux (positive for heat given up by the ocean to the atmosphere) and the SST tendency will indicate the regions where SST is forced by atmospheric conditions driven by the large-scale atmospheric circulation. On the other hand, positive correlations between the turbulent heat flux and SST (not SST tendency) may indicate the regions where the flux is driven by SST, or where SST anomalies are more strongly affected by oceanic processes rather than by the atmospheric circulation (Cayan 1992).

We used the OAFlux products for the turbulent flux and the ERSST dataset for the SST to carry out the correlation analysis separately for two periods: before and after 1990. This is because all winter surface variables examined here show abrupt changes in the late 1980s especially in the East Asian marginal seas, with a cold and high wind regime during the period 1970-89 and a warm and low wind regime during the period 1990-2005.
A more critical reason for limiting the analysis to interannual time scales in the above two periods is the lack of reliability of decadal-scale variability in the global-dataset-derived surface variables and turbulent fluxes in the western boundary region. To see this more clearly, we present in the online supplementary material the validation of the surface variables and turbulent fluxes from the NCEP-NCAR reanalysis. When compared with observation-derived datasets, the NCEP-NCAR wind speed and SST in the western boundary region are found to be so largely overestimated since 1990 s that even the sign of the decadal trend of the corresponding turbulent fluxes is highly suspicious. Such errors in decadalscale turbulent flux variations may not be limited to the NCEP-NCAR reanalysis but are likely to be a general tendency in other flux datasets too. To verify this presumption, we have reexamined wind speed anomalies from the NCEP-NCAR, OAFlux, and Trenberth geostrophic wind datasets (Fig. 5). We see that neither the NCEP-NCAR nor the OAFlux dataset shows a weakening wind tendency in recent decades in the western boundary region $\left(30^{\circ}-40^{\circ} \mathrm{N}, 120^{\circ}-135^{\circ} \mathrm{E}\right)$, while both show a strengthening tendency in the Kuroshio and $\mathrm{KOE}$ regions $\left(30^{\circ}-40^{\circ} \mathrm{N}, 140^{\circ}-170^{\circ} \mathrm{E}\right)$. In contrast, the Trenberth geostrophic wind speed shows a noticeable weakening in the former region (Fig. 5a), consistent with the well-known abrupt decline of the EAWM in recent decades, and a strengthening tendency in the latter regions (Fig. 5b), much like the NCEP-NCAR and OAFlux wind speeds. This means that both the NCEPNCAR and OAFlux wind datasets are inadequate for describing the recent decline in the EAWM in the 
(a) Turb Flux vs SST Tendency for 1970-1989

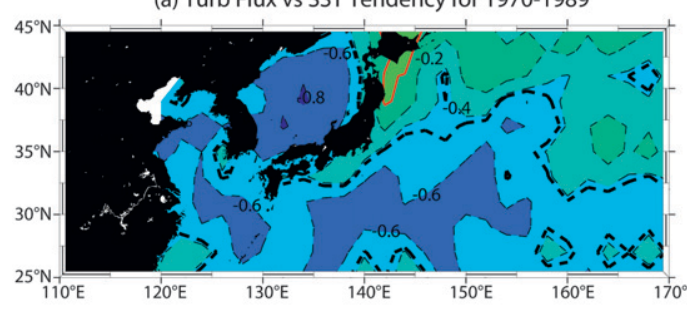

(c) Turb Flux vs SST for 1970-1989

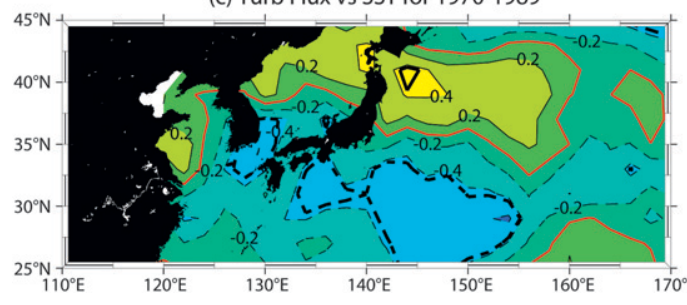

(b) Turb Flux vs SST Tendency for 1990-2005

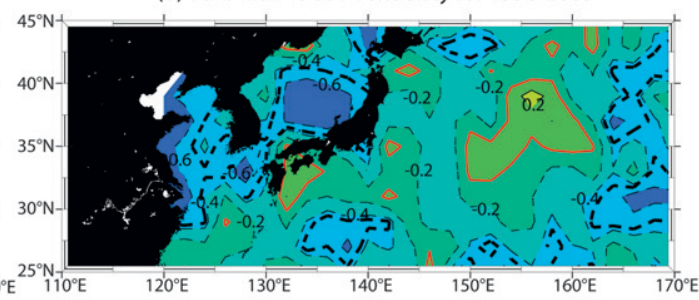

(d) Turb Flux vs SST for 1990-2005

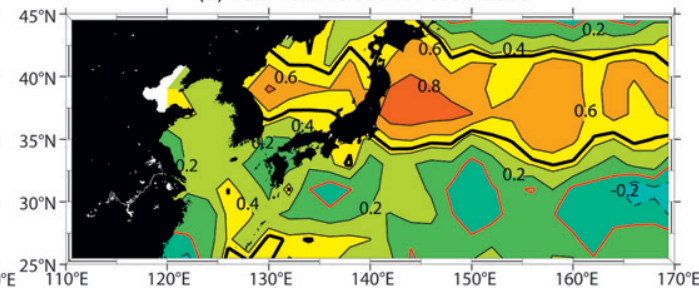

FIG. 6. Maps of the correlation coefficients between the OAFlux turbulent flux anomalies and SST tendency anomalies for (a) 1970-89 and (b) 1990-2005. (c),(d) As in (a),(b), but for SST anomalies. The boundary of significant correlations is marked by boldface lines and the zero contours are shown in red.

western boundary region, although they show a coherent positive trend in the interior North Pacific east of Japan. The weakening of the OAFlux wind around Korea as seen in Fig. 5 of Yu (2007) is somewhat tricky because this figure represents only the wind speed difference between the 1990s and the 1970s for which our Fig. 5 also reveals a minor decrease in the 1990s compared to the 1970s, despite the overall weak positive trend over the whole period of 1970-2005. As the OAFlux products are constructed by an optimal analysis combining surface variables from satellite observations as well as the NCEP-NCAR and European Centre for Medium-Range Weather Forcasts (ECMWF) reanalysis datasets (Yu and Weller 2007), it is not surprising that the OAFlux wind speed reveals a similar flaw as that of the NCEP-NCAR data in the western boundary region. Moreover, the satellite wind observations are injected into the OAFlux analysis after 1987 only (Yu and Weller 2007), which obviously cannot constrain the decadal trend over the periods before and after that year. For these reasons, our analysis below was made using the detrended OAFlux and ERSST datasets for two periods: before and after 1990 .

In the period 1970-89, SST tendency anomalies have negative correlations with turbulent flux anomalies in the quasi totality of the western North Pacific (Fig. 6a), with significant correlations appearing in the vast area including the Kuroshio Extension and its recirculation region as well as most of the marginal seas. This indicates that in the 1970s and 1980s increased sea-to-air fluxes associated with the strong EAWM led to decreasing SSTs in a large part of the western North Pacific.
The interpretation of the correlations between the SST and turbulent flux (Fig. 6c) is less evident, with negative correlations over most of the region south of $35^{\circ} \mathrm{N}$ and insignificant positive correlations north of $35^{\circ} \mathrm{N}$.

During the period 1990-2005, the sign of the correlations between the SST tendency and the turbulent flux remains negative in most parts of the western North Pacific (Fig. 6b); however, the area with significant correlations disappears almost completely along the Kuroshio path and in the KOE region. Furthermore, the correlation between the SST and turbulent flux becomes positive almost everywhere (Fig. 6d), with significant correlations concentrated in the $\mathrm{KOE}$ region and JES. There is a strong suggestion from these figures (especially Fig. 6a and Fig. 6d) that the role of the ocean in SST variability is increasingly important during the period 1990-2005, especially in the KOE region, as compared with the earlier period when the atmosphere played the major role. We will come back to this point in section $5 \mathrm{c}$ with a more quantitative analysis.

\section{SST variability and ocean dynamics}

\section{a. Lagged SST response to basinwide wind stress curl}

Previous studies (Seager et al. 2001; Sugimoto and Hanawa 2009) showed that SST anomalies in the KOE region are associated with the north-south displacement of the subtropical-subpolar gyre confluence, which is in turn associated with the latitudinal shift of the westerlies on the southern flank of the AL and of the line of zero wind stress curl. In view of this previous knowledge, it is 


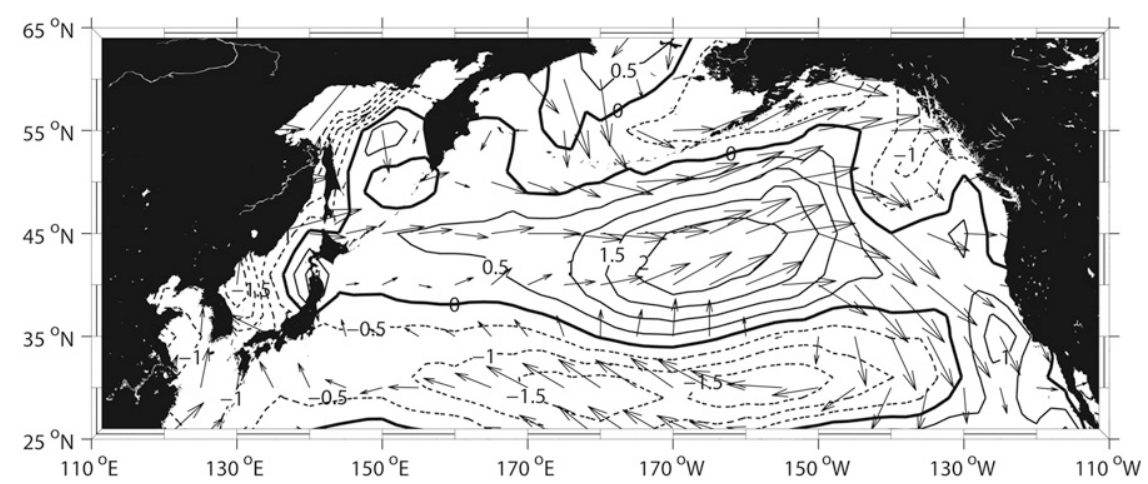

FIG. 7. Map showing the decadal-time-scale changes in DJF geostrophic winds over the North Pacific calculated as the period 1997-2003 minus the period 1980-86. Positive (negative) wind speed anomalies $\left(\mathrm{m} \mathrm{s}^{-1}\right)$ are shown by solid (dotted) contours.

instructive to see first the recent decadal-scale changes in the large-scale atmospheric circulation in the North Pacific, an example of which is given in Fig. 7 as the mean differential winds during 1997-2003 relative to 1980-86. The former (latter) period corresponds to the warmest (coldest) SSTs and weakest (strongest) EAWM in the western boundary region (see Fig. 4a). According to Sugimoto and Hanawa (2009), these two periods correspond also to a strong phase of AL but with its center being shifted significantly more northward (southward) than normal during 1997-2003 (1980-86). We have chosen these extreme periods to emphasize the clearest evidence for the tight connection between the recent abrupt change in the SST and wind field of the SH and AL circulation systems, which has occurred between the two chosen periods. (A similar result is obtained for 1990-2005 minus 1970-89, albeit with a somewhat less marked difference.)

Figure 7 reveals a basinwide anomalous anticyclonic circulation pattern centered at about $35^{\circ} \mathrm{N}$, with anomalous westerlies (easterlies) north (south) of $35^{\circ} \mathrm{N}$ reaching up to $>2 \mathrm{~m} \mathrm{~s}^{-1}\left(<-1.5 \mathrm{~m} \mathrm{~s}^{-1}\right)$ in the central North Pacific. As the climatological winter winds north of $25^{\circ} \mathrm{N}$ are westerlies (see Fig. 2), the anomalous anticyclone suggests a northward shift of the AL in the more recent period compared to the earlier period, in agreement with Sugimoto and Hanawa (2009). Hori and Ueda (2006) showed that the appearance of the anomalous anticyclone, in conjunction with the northward shift of the $\mathrm{AL}$ and the decline of the SH and EAWM, constitutes one of the most outstanding features under the global warming scenario. In the marginal seas anomalous southerlies of $1.0-1.5 \mathrm{~m} \mathrm{~s}^{-1}$ are observed, consistent with the recent abrupt weakening of the EAWM discussed in the appendix (see Fig. A1).

To show the delayed ocean response to changes in surface atmospheric circulation of the AL system during the two contrasting periods before and after 1990, we performed a lag correlation analysis between the basinwide DJF wind stress curl (WSC) anomalies and JFM SST anomalies at each grid point, separately for 1970-89 and 1990-2005 (Fig. 8). We used the NCEPNCAR WSC averaged over the central North Pacific region $\left(32^{\circ}-38^{\circ} \mathrm{N}, 150^{\circ} \mathrm{E}-140^{\circ} \mathrm{W}\right)$, referred to as the WSC index (WSCI), although the results are not very sensitive to the exact choice of the averaging region. Unlike that in the western boundary region close to the Asian coast, the NCEP-NCAR wind speed east of Japan presents quite similar interannual to decadal-scale variations to those for the Trenberth geostrophic wind speed (see Fig. 5), suggesting no serious errors in the NCEP-NCAR wind data in the interior North Pacific, which may justify our use of the NCEP-NCAR wind stress data there.

At the zero lag for both periods (Figs. 8a,b), significant negative correlations are confined south of $35^{\circ} \mathrm{N}$ and west of $150^{\circ} \mathrm{W}$, with the strongest correlations $(r<-0.6)$ being concentrated close to the south-central flank of the domain. Note that a negative correlation means that a positive (negative) SST anomaly is related to an anomalous anticyclone (cyclone). This seems to correspond to a local and instantaneous response of the region to varying wind forcing via Ekman drift (Seager et al. 2001). As Ekman drift is proportional to the wind stress, this interpretation is supported by correlation maps of wind stress versus WSCI (see Figs. 9c,d), which show significant positive (negative) correlations to the south (north) of the KOE latitudes $\left(35^{\circ}-40^{\circ} \mathrm{N}\right)$. The sign of the correlations between SST and WSCI also changes across the KOE latitudes, with strong positive correlations being widely developed around $45^{\circ} \mathrm{N}$ in 1990-2005 (Fig. 8b), in contrast to mostly insignificant correlations in 197089 (Fig. 8a). This seems to be related to the abovementioned anomalous anticyclone evidenced in the former period (see Fig. 7), which is associated with 

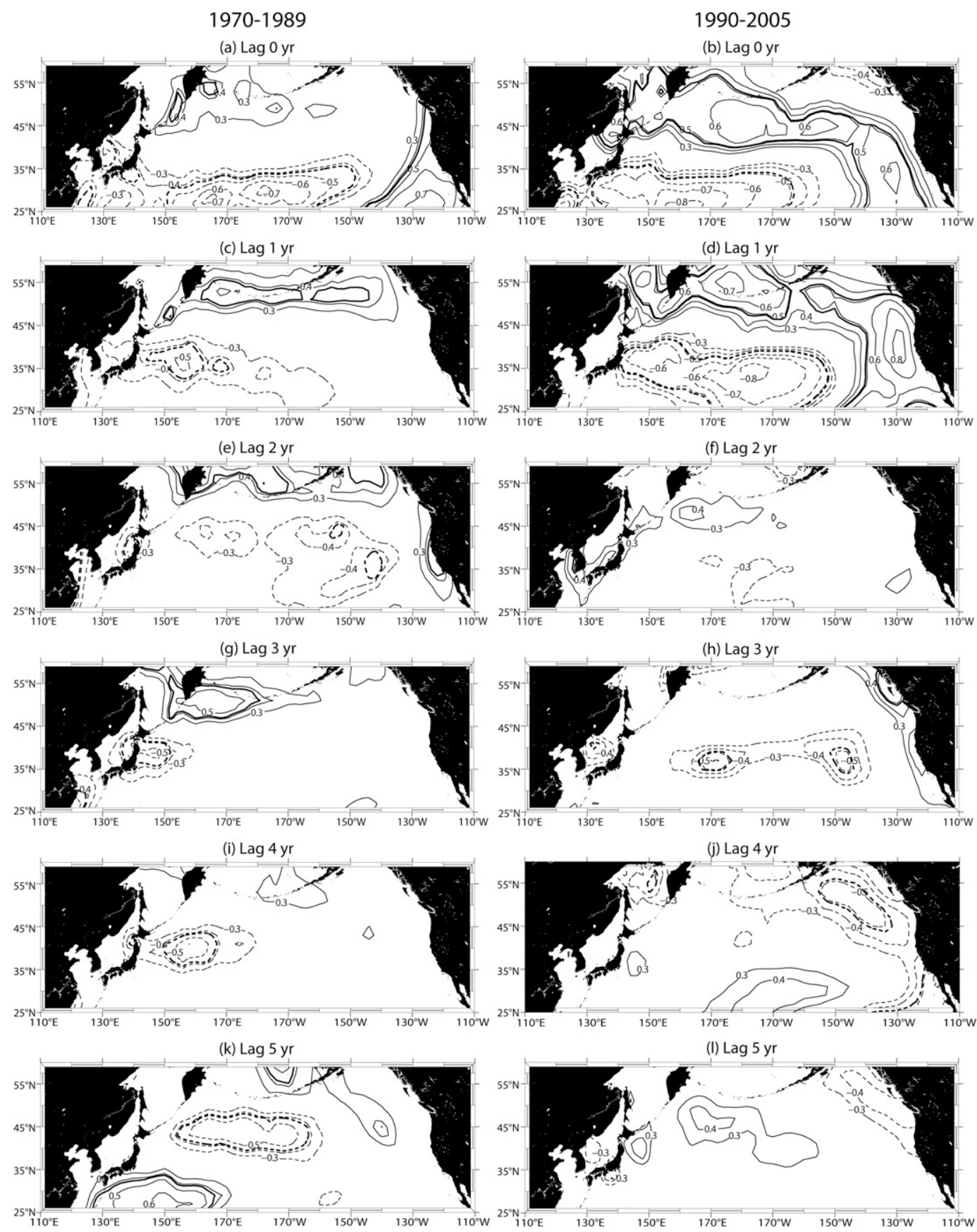

FIG. 8. Maps showing the correlation coefficients between DJF WSCI anomalies and lagged JFM SST anomalies, separately for (a),(c),(e),(g),(i),(k) 1970-89 and (b),(d),(f),(h),(j),(l) 1990-2005. Only absolute correlations $>0.3$ are shown, with the boundary of significant correlations being marked by boldface lines.

significantly strengthened (weakened or reversed) westerlies around $45^{\circ} \mathrm{N}\left(30^{\circ} \mathrm{N}\right)$ in the central North Pacific.

At the lag of $1 \mathrm{yr}$ (Figs. 8c,d), the ensemble pattern of significant correlations shifts northward by about $5^{\circ}$ relative to the zero-lag case, with negative correlations now covering the entire KOE region. In particular, significant negative correlations in 1990-2005 are much stronger and extensively developed as far as the central basin as compared with moderate correlations limited to the $\mathrm{KOE}$ region in 1970-89. Although noticeable positive correlations are also observed in the northern and eastern boundary regions, our discussion hereafter will be limited 

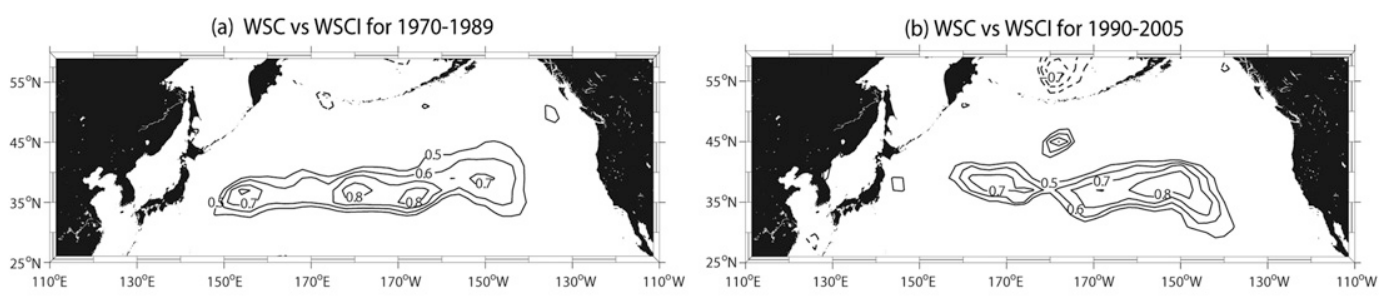

(c) WS vs WSCI for 1970-1989
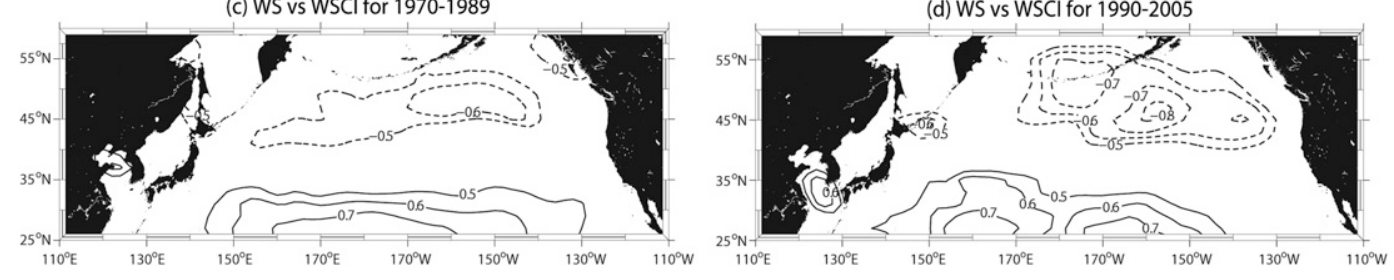

FIG. 9. Correlation coefficients between WSCI and WSC at each grid point for (a) 1970-89 and (b) 1990-2005. (c),(d) As in (a),(b), but for zonal wind stress instead of WSC. Only significant correlation coefficients are shown at intervals of 0.1 .

to the KOE region. At the lag of 2 yr (Figs. 8e,f), significant correlations disappear completely from the KOE region for both periods. For 1970-89, an interesting feature occurs at lags of 3 and 4 yr (Figs. $8 \mathrm{~g}, \mathrm{i}$ ) by the reappearance of significant negative correlations that are confined in the KOE region. On the contrary, no comparable feature appears in the western North Pacific in 1990-2005 (Figs. 8h,j). At a lag of 5 yr, there are no significant correlations in the KOE region for either period (Figs. 8k,l).

\section{b. Epoch-dependent delayed response of the KOE SST to WSC forcing via Rossby waves}

For interpreting these lag correlations, we find that the schematic diagrams of the lagged patterns of decadal SST response in the North Pacific of Miller et al. (2004) are particularly interesting and instructive. According to these authors, the delayed SST response in the western North Pacific, especially in the KOE region, is largely controlled by the thermocline response to WSC forcing associated with a decadal change in the AL. In addition, the thermocline change drives the change in ocean dynamics due to the gyre circulation adjustment that is achieved by the westward propagation of baroclinic Rossby waves from the central North Pacific, taking several years for the KOE response. In view of this, Fig. 8 indicates that the KOE SST reveals two epochdependent delayed modes of response to the basinwide WSC forcing: a rapid response lagged by $1 \mathrm{yr}$ and a slow response lagged by $3-4$ yr. Before investigating the causes of these different epoch-dependent lags, we present in Table 2 correlations of WSCI, PDOI, and EAWMI with the lagged KOE SST for three different periods (1970-2005, 1970-89, and 1990-2005). Here, the KOE SST has been averaged over the area $\left(35^{\circ}-40^{\circ} \mathrm{N}, 142^{\circ}-\right.$ $\left.160^{\circ} \mathrm{E}\right)$. For the entire analysis period (1970-2005), the KOE SST is significantly correlated with WSCI at the 1- and 3-yr lags but only marginally correlated at the 4-yr lag. In the two subperiods, significant correlations are found at lags of 1, 3, and $4 \mathrm{yr}$ for 1970-89 but only at $1 \mathrm{yr}$ for 1990-2005, consistent with Fig. 8. Also, the strongest correlations are always found at the 1-yr lag and there is a gap of significant correlation at the $2-\mathrm{yr}$ lag, regardless of period. It is also interesting to note that contrary to the earlier period, the KOE SST for 1990-2005, which shows the strongest correlation of all

TABLE 2. Lag correlations of WSCI, PDOI, and EAWMI with lagged winter KOE SST anomalies for different periods. Other comments are the same as in Table 1.

\begin{tabular}{|c|c|c|c|c|c|c|c|c|c|}
\hline \multirow[b]{2}{*}{ Lag (yr) } & \multicolumn{3}{|c|}{ WSCI } & \multicolumn{3}{|c|}{ PDOI } & \multicolumn{3}{|c|}{ EAWMI } \\
\hline & 1970-2005 & 1970-89 & 1990-2005 & 1970-2005 & 1970-89 & 1990-2005 & 1970-2005 & 1970-89 & 1990-2005 \\
\hline 0 & -0.22 & -0.10 & -0.27 & -0.48 & -0.47 & -0.73 & -0.54 & -0.53 & -0.06 \\
\hline 1 & -0.62 & -0.51 & -0.78 & -0.31 & -0.43 & -0.10 & -0.57 & -0.45 & -0.35 \\
\hline 2 & -0.28 & -0.23 & -0.01 & -0.12 & -0.15 & -0.13 & -0.28 & 0.20 & -0.38 \\
\hline 3 & -0.47 & -0.49 & -0.08 & -0.02 & 0.01 & -0.17 & -0.02 & 0.01 & -0.16 \\
\hline 4 & -0.33 & -0.50 & 0.27 & -0.06 & -0.24 & 0.16 & -0.27 & 0.10 & -0.10 \\
\hline 5 & -0.10 & -0.12 & 0.21 & -0.14 & -0.53 & 0.29 & -0.16 & 0.16 & 0.12 \\
\hline
\end{tabular}


periods at the 1-yr lag, misses a significant slow response (at lags of $3 \mathrm{yr}$ and more) to the basinwide WSC forcing. We will come back to this point later in this section.

In contrast to the lagged impact of WSC, PDOI always has significant synchronous correlations with the KOE SST, except for 1970-89 when it also shows another significant correlation at the 5-yr lag. Also, PDOI reveals its strongest in-phase correlation during 1990-2005, which is in great contrast with EAWMI, which does not show any significant correlation in this period. In 1970-89, however, EAWMI has significant correlations with the KOE SST at both 0- and 1-yr lags. A supplementary lag correlation analysis between different indices for 1970-2005 indicates that at the zero lag WSCI is significantly correlated with EAWMI $(r=0.52)$ and the WP index $(r=$ $-0.60)$ but not with PDOI $(r=0.09)$ and ALI $(r=-0.07)$, although it has a marginal correlation $(r=0.38)$ with 1-yr lagged PDOI. Note finally that ALI does not show any significant lag correlation with either WSCI or EAWMI. These results are somewhat inconsistent with previous studies (e.g., Qiu 2003), which emphasize the dominance of the PDO-related WSC variations in the AL system.

We have shown that, depending on the epoch, there exist a few well-distinct time lags of the significant KOE SST response to the basinwide WSC forcing, which could be related to different arrival times of Rossby waves generated at different centers of action of WSC forcing. To check this possibility, we show in Figs. 9a,b correlations between WSCI and WSC at each grid point, respectively, for 1970-89 and 1990-2005. In the former period there exists a zonally elongated band of strong correlations centered at around $36^{\circ} \mathrm{N}$ between $150^{\circ} \mathrm{E}$ and $140^{\circ} \mathrm{W}$, with four local maxima or centers of action located at about $155^{\circ} \mathrm{E}, 180^{\circ} \mathrm{E}, 165^{\circ} \mathrm{W}$, and $150^{\circ} \mathrm{W}$, respectively. In the latter period, while the ensemble pattern is somewhat similar to the earlier period, the centers of action appear to be more compact and shifted eastward by about $10^{\circ}-20^{\circ}$ longitude, showing only two welldistinct centers: a minor one in the western basin at about $165^{\circ} \mathrm{E}$ and a major one in the eastern basin at $155^{\circ} \mathrm{W}$. According to Qiu (2003), the westward Rossby wave speed at $36^{\circ} \mathrm{N}$ is $\sim 2.8 \mathrm{~cm} \mathrm{~s}^{-1}$, which will travel about $10^{\circ}$ longitude in a year. Taking this wave speed, Rossby waves generated at each center of action will arrive at the $\mathrm{KOE}$ region center $\left(150^{\circ} \mathrm{E}\right)$ in about $0.5,3,4.5$, and 6 yr for 1970-89, whereas they will arrive in about 1.5 and $5.5 \mathrm{yr}$ for 1990-2005. Except for the case of the easternmost center of action for each period, these theoretical arrival times of Rossby waves are consistent within $\pm 0.5 \mathrm{yr}$ with the above-mentioned time lags $(1,3$, and $4 \mathrm{yr}$ for the former period and $1 \mathrm{yr}$ for the latter period) obtained from the lag correlation between the
KOE SST and WSCI. The absence of a significant correlation at the lag of $5.5 \mathrm{yr}$ for 1990-2005 can be explained by taking in account the exponential decay of Rossby waves with time, $\sim \exp \left(-t / t_{s}\right)$ (e.g., Qiu 2002). Here, $t$ is the traveling time of a Rossby wave from its generation site to an observation site and $t_{s}$ is a decay time scale for which Schneider et al. (2002) and Qiu (2002) suggested 4 and 6 yr, respectively. Taking a mean value of $t_{s}=5 \mathrm{yr}$, a Rossby wave arriving at the lag of $5.5 \mathrm{yr}$ will be reduced to about $33 \%$ of its original amplitude, as compared with $82 \%$ for the 1-yr lag, thus making its detection harder especially in the highly energetic, eddypopulated KOE region. In this sense our results for 19902005 are consistent with the failure of a linear Rossby wave model-based SSH hindcast in the KOE region by Qiu (2003), who used PDO-related WSC forcing showing its predominant center of action centered at about $160^{\circ} \mathrm{W}$ (see his Fig. 2) and validated his results in comparison with the Ocean Topography Experiment (TOPEX)/ Poseidon altimeter data for 1992-2002.

Above arguments with Rossby waves involve the anomalous advection of mean temperature, $\mathbf{v}^{\prime} \nabla \bar{T}$, which may arise, for example, from the modulation in latitude and strength of the oceanic fronts associated with the Kuroshio-Oyashio confluence. An alternative term to consider would be $\overline{\mathbf{v}} \nabla T^{\prime}$, that is, the advection of temperature anomalies by the mean velocity. The mean anticyclonic subtropical gyre circulation may advect SST anomalies found in the gyre recirculation region to the KOE region. We have checked this possibility first for the case of Ekman drift-driven SST anomalies in the southern flank of the central North Pacific $\left(25^{\circ}-30^{\circ} \mathrm{N}\right.$, $\left.150^{\circ} \mathrm{E}-150^{\circ} \mathrm{W}\right)$, which have already been mentioned in the previous subsection by interpreting Figs. 8a,b in comparison with Figs. 9c,d. We used for this a simple advection-diffusion numerical model and the mean geostrophic velocity field derived from the "Rio05" mean dynamic topography (MDT) model (Rio and Hernandez 2004). The results (not shown) indicate no evidence of SST signals arriving in the KOE region even in several years because of too weak (a few centimeters per second) interior circulation of the gyre. Only SST anomalies initially put along the southern flank of the East China Sea, where the swift Kuroshio main stream is encountered, can arrive at the KOE region in less than a year. Recall that the East China Sea is under strong influence from the EAWM (see Fig. 3) and that the latter is significantly correlated with WSCI at the zero lag, as mentioned previously. Therefore, the persistent significant correlation at the $1-\mathrm{yr}$ lag between the KOE SST and WSCI could arise due at least partly to mean advection via the Kuroshio of the anomalous SST caused by the changing EAWM in the southern East China Sea. 
(a) KOESST (bk), -EAWMI (bl), -WSCl-1yr (r)

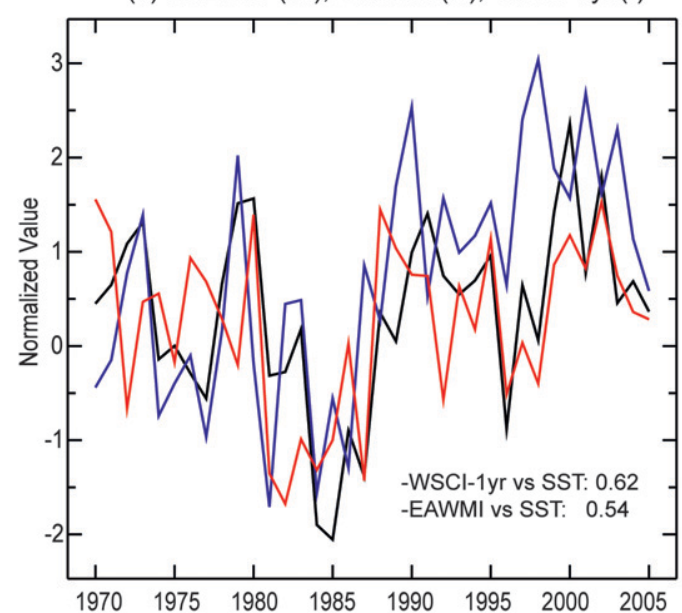

(b) KOESST vs -(aEAWMI + bWSCl-1yr)

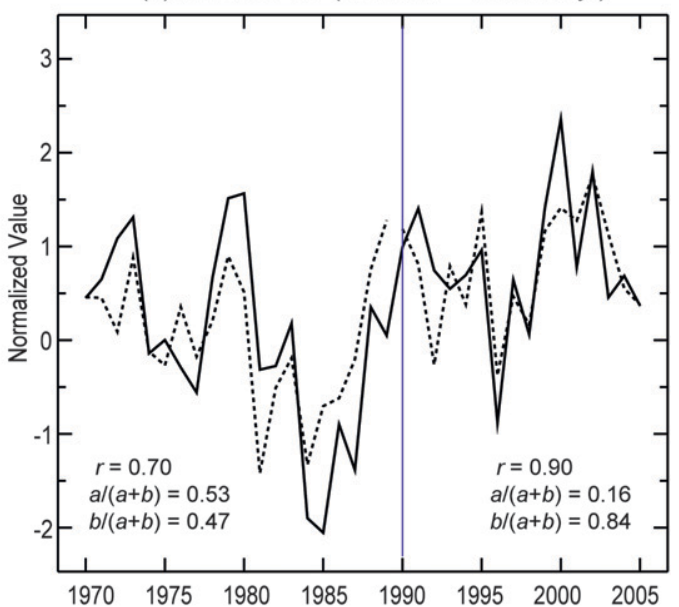

FIG. 10. (a) Winter (JFM) SST anomalies averaged in the KOE region $\left(35^{\circ}-40^{\circ} \mathrm{N}, 142^{\circ}-160^{\circ} \mathrm{E}\right.$; black) as compared with the negative WSCI anomalies of the precedent year (WSCI-1yr, red) and EAWMI anomalies (blue). All time series have been previously normalized. Also inserted are the correlation coefficients between the SST anomalies and each of -WSCI-1yr and-EAWMI anomalies. (b) Comparison of the KOE SST anomalies (solid) and the regressed time series (dotted),$-(a$ EAWMI $+b$ WSCI-1yr), obtained by a multivariate regression analysis (see the text) for 1970-89 and 1990-2005, respectively. The resulting optimal correlation coefficient $r$ and the relative contribution ratios of both variables, $a /(a+b)$ and $b /(a+b)$, are also indicated.

\section{c. Relative contributions of the EAWM and ocean dynamics to the SST variability}

Here, we tested whether the dual contribution from both the EAWM and ocean dynamics represented by WSCI preceded by $1 \mathrm{yr}$ (WSCI-1yr) brings any significant improvement to the correlation with the western North Pacific SST, especially for the period after 1990 during which there is evidence of the increasing role played by the ocean, as remarked upon in section 4. A more complete analysis taking into consideration a longer time lag (e.g., WSCI-3yr) is left for a future study. In the KOE region for the entire analysis period (1970-2005), the area-mean SST anomalies are significantly correlated with both EAWMI $(r=-0.54)$ and WSCI-1yr $(r=-0.62)$, each accounting separately for a comparable amount $(29 \%-36 \%)$ of the total SST variance (Fig. 10a). Figure 10b represents a comparison between the KOE SST anomalies and the regressed SST anomalies with negative EAWMI and WSCI-1yr, separately for 1970-89 and 1990-2005. We used here a similar multivariate regression analysis to that detailed in section 3, but with the regression coefficients $a$ and $b$ now representing EAWMI and WSCI-1yr, respectively. For the sake of brevity in terminology, we also set $\alpha=$ $a /(a+b)$ and $\beta=b /(a+b)$ for designating the relative contribution ratios of EAWMI and WSCI-1yr, respectively. Here, we observe a noticeable improvement in correlation especially for 1990-2005 $(r=0.9)$ during which ocean dynamics (WSCI-1yr) played a predominant role $(\beta=0.84)$, explaining $58 \%$ of the total SST variance as compared with a near-zero contribution by the EAWM. This is in contrast to the earlier period (1970-89) showing instead a slightly greater contribution from the EAWM ( $\alpha=0.53$ ), which explains $28 \%$ of the total SST variance as compared with $25 \%$ by the ocean dynamics. It is to be noted that there could be some potential limitations on the interpretation of the multiple regression if the predictor variables are highly intercorrelated, a feature often called multicolinearity (cf. http://www.ltrr.arizona.edu/ dmeko/ notes_11.pdf). However, this problem of multicolinearity may be negligible in our case because the correlation between WSCI-1yr and EAWMI is rather quite low or insignificant ( $r=0.15$ for $1970-89 ; r=0.05$ for 1990 $2005)$, in great contrast to the high in-phase correlation between WSCI and EAWMI, as already mentioned in the previous subsection.

A detailed geographical distribution of the relative contribution $\beta$ from ocean dynamics is shown in Fig. 11. In the period 1970-89 the quasi totality of the marginal seas reveals a minor contribution $(<20 \%)$ from ocean dynamics, indicating the predominance of the EAWM in controlling winter SST variability of the region, except for the northwestern Yellow Sea (Bohai Sea) where abnormal $\beta$ values $(>0.4)$ are found in isolation from adjacent seas, for unknown reasons. The predominance of the EAWM is not limited to the marginal seas but extends to the western boundary current region close to 
(a) Contribution from WSCl-1yr for 1970-1989

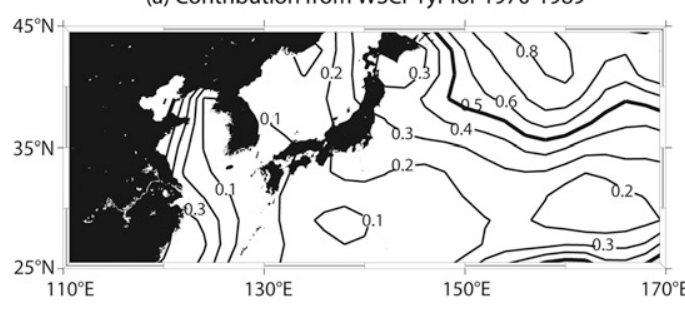

(b) Contribution from WSCl-1yr for 1990-2005

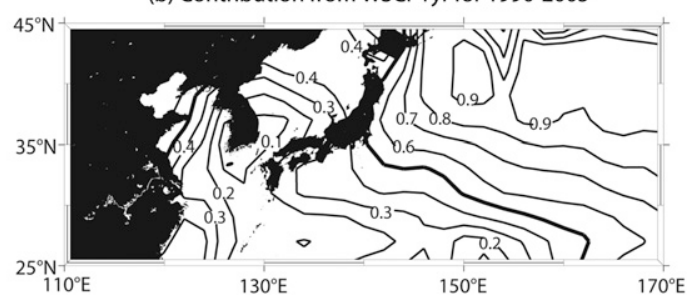

FIG. 11. Maps showing the spatial distribution of the relative contribution ratio of ocean dynamics, $b /(a+b)$, for (a) 1970-89 and (b) 1990-2005. Note that the contribution ratio of the EAWM is $1-b /(a+b)$. The boundary of the equal contributions from ocean dynamics and the EAWM is marked by boldface lines.

the east coast of Japan as well as the vast Kuroshio recirculation area southeast of Japan where ocean dynamics account for less than $30 \%$ of the contribution. The only area where ocean dynamics are a major contributor $(\beta>0.5)$ is found in the northeastern part of the domain, north of $38^{\circ} \mathrm{N}$ and east of $150^{\circ} \mathrm{E}$.

In the period 1990-2005 the situation is dramatically changed, especially in the entire Kuroshio and Oyasio current system east of Japan, where ocean dynamics far dominate over the EAWM $(1>\beta>0.5)$, with its greatest contributions of as much as $\beta>0.9$ being centered at $40^{\circ} \mathrm{N}$ along the northern boundary of the KOE region. The marginal seas and the Kuroshio recirculation region also show a significant increase in $\beta$ values (by $0.1-0.2$ ) compared to the earlier period, so that ocean dynamics now make a substantial contribution $(30 \%-50 \%)$ in most of the JES and the Kuroshio recirculation region. These results nicely support the qualitative inference made independently from the turbulent flux-SST relationship discussed in section 4 . Note that there are remarkable one-to-one correspondenced between Fig. 6a and Fig. 11a for 1970-89 and between Fig. 6d and Fig. 11b for 1990-2005. Our results are consistent with those of Kelly (2004), who showed using a simple assimilation model of the upper-ocean heat budget for the period 1970-2000 in the western North Pacific that the largest oceanic heat transport balancing the largest heat loss from the ocean occurred in the 1990s. These findings are also consistent with the results of Kawai et al. (2008), who showed that in the 1980s the Ekman transport contributed dominantly to the meridional heat transport across $24^{\circ} \mathrm{N}$ in the Pacific Ocean, while in the 1990s the Kuroshio temperature transport dominated the meridional heat transport, especially in the Kuroshio and KOE regions.

\section{Summary and discussion}

On the basis of the correlation analysis between the SST and different atmospheric and oceanic forcing parameters, we have attempted in the present paper to explain the possible causes of the recent unusual warming of the western North Pacific in relation to the decadalscale changes of the SH and AL.

From an extensive comparison with observationderived winter surface variables in the marginal seas region (see the appendix), a new EAWMI is proposed as the normalized SLP difference between the two eastern centers of action of the Eurasian teleconnection pattern (i.e., the central region of the $\mathrm{SH}$ and the JES center). Relative to previous indices, this new index shows outstanding performance in explaining the variability of winter surface variables over the western North Pacific (Table A1). The primary reason for this superiority may lie in the fact that our new EAWMI uses two teleconnection centers having opposite polarity, which should yield the strongest negative relationship between them when compared with any other pairs of stations. This allows the SLP difference between the two centers to have the strongest correlation with the EAWM, by geostrophy. The recent abrupt decline of the EAWM owes its existence nearly entirely to the unprecedented weakening of the SH, suggesting that either of EAWMI or SHI can be efficiently used for studying the EAWM in the western North Pacific.

We have emphasized the lack of reliability found in the decadal-scale changes in the global dataset-derived surface variables and turbulent flux in our western boundary region. For example, we have shown in the online supplementary material that the NCEP-NCAR surface variables such as wind speed and SST are highly overestimated, with a mean overestimation in the period $1990-2005$ by up to $0.9 \mathrm{~m} \mathrm{~s}^{-1}$ and $1.0^{\circ} \mathrm{C}$, especially in the East China Sea, which should have led to a large overestimation in the NCEP-NCAR turbulent flux. We have diagnosed, using a simple flux adjustment method, that the NCEP-NCAR turbulent flux data are indeed in great error especially in the western boundary region, with an astonishing overestimation by as much as $120 \mathrm{~W} \mathrm{~m}^{-2}$ in the East China Sea. In section 4 we have further verified that the other global dataset (i.e., OAFlux) also fails to correctly represent the recent abrupt decline of the EAWM in the western boundary region (Fig. 5a), 
suggesting suspicious decadal-scale variability of the corresponding turbulent flux. This means that for this western boundary region, only interannual variability can be relatively safely studied from these datasets. Indeed, using the detrended OAFlux for two periods before and after 1990, we have obtained the first useful information on the relative importance of the atmosphere and ocean (Fig. 6), which is verified by a more quantitative method summarized later in this section.

A lag correlation analysis between SST anomalies and WSCI separately for the two contrasting periods before and after 1990 (Fig. 8) has permitted us to demonstrate how the SST in the western North Pacific responds in an epoch-dependent delayed mode to changes in the surface atmospheric circulation of the AL system. At the zero lag, a local and instantaneous response via Ekman drift is concentrated around $30^{\circ} \mathrm{N}$ near the southern boundary of the AL in both periods, but in the later period another significant response of opposite polarity is also observed around $45^{\circ} \mathrm{N}$, which is likely related to strong decadal-scale changes in wind field in association with the recent meridional shift of the AL (Fig. 7). The delayed response of the KOE SST to basinwide wind stress curl forcing via Rossby waves is epoch-dependent (Table 2), with lags of 1, 3, and $4 \mathrm{yr}$ before 1990 but only at the lag of 1 yr after 1990. This epoch dependency of the impact of Robby waves is found to be related to the zonal distribution of centers of action of WSC forcing, which varies with period. The persistent fast response (1-yr lag) is related to the quasipermanent existence of a center of action located close to the $\mathrm{KOE}$ region. In addition, anomalous SSTs caused by the changing EAWM in the southern East China Sea are likely carried by the mean currents of the Kuroshio to affect the KOE SST in about a year. The absence of a slow response (lags of 3 yr or more) after 1990 can be explained by a far eastward shift of the main center of action of WSC by up to $20^{\circ}$ longitude relative to the earlier period; over their longer travel time, Rossby waves thus undergo substantial decay before arriving at the KOE region.

One of the most original approaches attempted in the present study may be the quantitative evaluation of the relative contributions of the EAWM and ocean dynamics (represented by a basinwide WSC index of the precedent year) to local SST variability in the western North Pacific (Fig. 11). This figure, which can be considered to be a "highlight" of our major findings, demonstrates clearly that the EAWM is largely responsible for winter SST variability during 1970-89 in most parts of the western North Pacific, whereas during the period 19902005 it is ocean dynamics that exert the dominant control over the SST variability in the western boundary current region east of Japan, peaking along the northern boundary of the $\mathrm{KOE}$ region at $40^{\circ} \mathrm{N}$. Ocean dynamics has become increasingly important in other places too, such as the JES and the Kuroshio recirculation region where there appears to be a substantial (30-50\%), if not dominant, contribution from ocean dynamics during 1990-2005. Our results are somewhat different from those of Minobe et al. (2004), who showed using highly filtered data that on decadal time scales, the upper-layer temperature variations in the JES are principally associated with the SH intensity and secondarily with the AL intensity. While the tight connection of the JES temperature anomalies with the $\mathrm{SH}$ intensity is verified by both works, our analysis does not reveal any significant lag correlation with the AL intensity. In our case it is the wind stress curl change in the central North Pacific, which is mainly associated with the meridional displacement of the AL and not necessarily with its intensity (Sugimoto and Hanawa 2009), that significantly affects the SST of the western North Pacific, including the JES. It is also shown that WSCI is best correlated synchronously with EAWMI (and the WP index) but that no significant correlation is established between WSCI and ALI.

Finally, based on the results obtained here, we would like to make some concluding comments on the strongest positive SST trend observed in recent decades in the western North Pacific (Fig. 1). This remarkable ocean climate change may ultimately be interpreted as the consequence of the concomitant rapid change in both the $\mathrm{SH}$ and $\mathrm{AL}$ systems in recent decades, which affected significantly not only the large-scale atmospheric circulation over East Asia and the North Pacific but also the subtropical gyre circulation of the ocean. The westward-intensified positive SST trend in the East Asian marginal seas and the western boundary current region east of Japan may have resulted from the combined effects of the abrupt weakening of the EAWM due to the unprecedented decline of the $\mathrm{SH}$ and the increasing ocean's role by its 1-yr delayed response via the gyre circulation adjustment to the rapidly changing atmospheric circulation over the central North Pacific since the late 1980s. The latter feature is associated with the northward shift of the southern boundary of the strengthened AL, which has occurred in conjunction with the abrupt weakening of the SH and EAWM.

Acknowledgments. This work has been partly supported by the Japanese Ministry of Education, Culture and Science via an invitation to YHP for several months in 2005 and 2010 at the Research Institute of Advanced Mechanics, Kyushu University, Fukuoka, Japan. We thank three anonymous reviewers and the editor for 
(a) EAWM Indices

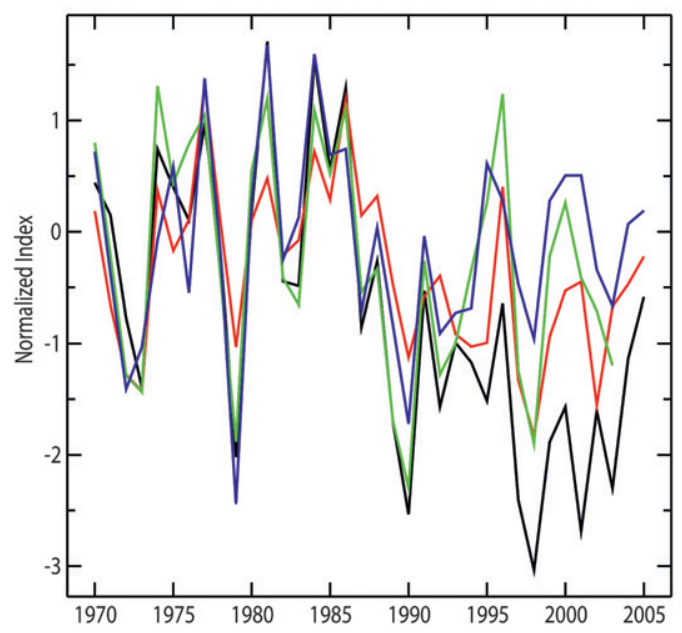

(b) Wind Speeds Around Korea

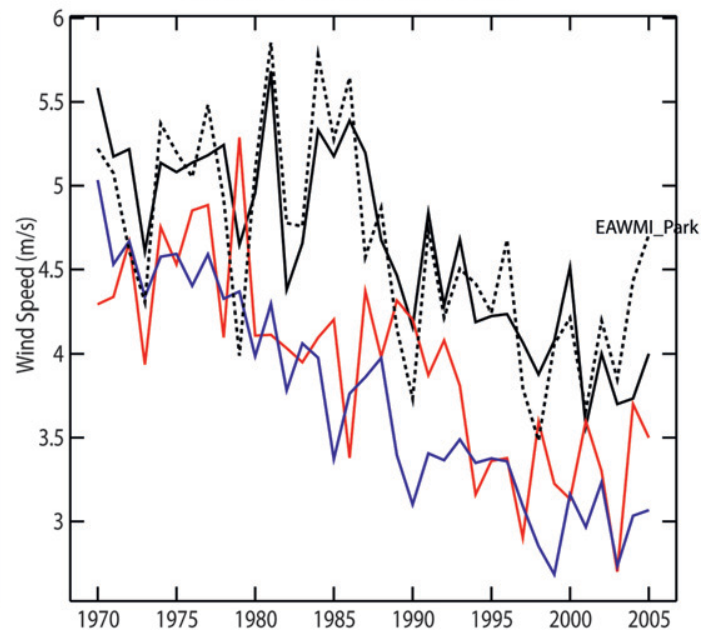

FIG. A1. (a) Comparison of time series of different EAWM indices: EAWM $\mathrm{Eark}_{\text {(black); EAWM }}$ (red);

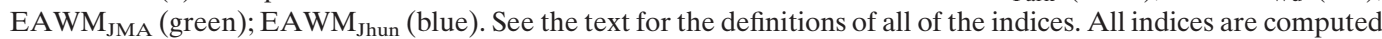
as normalized DJF values relative to the base period of 1970-89. (b) Time series of DJF wind speeds observed at three KMA island and coastal stations: Cheju (black), Ullung (red), Inchon (blue). An arbitrarily scaled EAWM $M_{\text {Park }}$ time series (dotted) is superimposed for comparison with the wind speed time series. See Fig. 2 for the location of the three KMA stations (green circles).

their constructive comments, which greatly improved the original version of this paper.

\section{APPENDIX}

\section{Validation of East Asian Winter Monsoon Indices}

Although a number of diverse definitions of the EAWM index have been proposed in the literature (Wang and Chen 2010), the most practical indices that are readily accessible from observation-derived surface variables seem to be those using a zonal SLP gradient, which should be proportional to the intensity of the northerly winter monsoon winds, by geostrophy. For example, $\mathrm{Wu}$ and Wang (2002) proposed as an index $\left(\mathrm{EAWM}_{\mathrm{Wu}}\right)$ the normalized SLP difference between two longitudes spanning the $\mathrm{SH}$ and $\mathrm{AL}, 110^{\circ}$ and $160^{\circ} \mathrm{E}$, averaged over a latitudinal band covering $20^{\circ}-70^{\circ} \mathrm{N}$. On the other hand, the Japanese community (e.g., Watanabe et al. 1987; Yasuda and Hanawa 1999; Senjyu et al. 1999; Tian et al. 2006, among others) preferentially use the Japan Meteorological Agency index $\left(\mathrm{EAWM}_{\mathrm{JMA}}\right)$ that is defined as the SLP difference between Irkutsk, Russia $\left(52.3^{\circ} \mathrm{N}\right.$, $104.3^{\circ} \mathrm{E}$ ), west of southern Baikal Lake and Nemuro $\left(43.3^{\circ} \mathrm{N}, 145.6^{\circ} \mathrm{E}\right)$, Hokkaido, Japan. Based on the NCEPNCAR reanalysis data, Jhun and Lee (2004) suggested an index $\left(\mathrm{EAWM}_{\mathrm{Jhun}}\right)$ as the upper-troposphere zonal wind shear at $300 \mathrm{hPa}\left(U_{300}\right): \mathrm{EAWM}_{\mathrm{Jhun}}=U_{300}\left(27.5^{\circ}-37.5^{\circ} \mathrm{N}\right.$, $\left.110^{\circ}-170^{\circ} \mathrm{E}\right)-U_{300}\left(50^{\circ}-60^{\circ} \mathrm{N}, 80^{\circ}-140^{\circ} \mathrm{E}\right)$. Youn $(2005)$ proposed using the SLP difference between the SH center $\left(45^{\circ} \mathrm{N}, 90^{\circ} \mathrm{E}\right)$ and JES center $\left(40^{\circ} \mathrm{N}, 135^{\circ} \mathrm{E}\right)$, which corresponds approximately to the two eastern centers of action of the Eurasian teleconnection pattern defined by Wallace and Gutzler (1981) and Barnston and Livezey (1987).

We extend here Youn's idea to suggest a new index $\left(\right.$ EAWM $\left._{\text {Park }}\right)$ as the normalized DJF SLP difference between the area-weighted SLP over the central region of the SH (where the DJF SLP climatology exceeds generally $1032 \mathrm{hPa}$ ) and that near the JES center: $\mathrm{EAWM}_{\text {Park }}=\operatorname{SLP}\left(45^{\circ}-55^{\circ} \mathrm{N}, 85^{\circ}-105^{\circ} \mathrm{E}\right)-\operatorname{SLP}\left(35^{\circ}-\right.$ $\left.40^{\circ} \mathrm{N}, 135^{\circ}-140^{\circ} \mathrm{E}\right)$. Considering their inherent spatiotemporal variations, the random observational errors in SLP at both centers are expected to be reduced by the spatial average, which permits our new index to indeed yield slightly better correlations with different wintertime surface variables as compared to Youn's index, which will not be further discussed hereafter. Moreover, our area-weighted SLP in the central region of the SH represents the intensity of the $\mathrm{SH}$, or the $\mathrm{SH}$ index (SHI), which is very close to that defined by Gong and Ho (2002) or Panagiotopoulos et al. (2005). Similarly, we define for later use the AL index as the area-weighted SLP averaged over the region $40^{\circ}-60^{\circ} \mathrm{N}, 160^{\circ} \mathrm{E}-160^{\circ} \mathrm{W}$, which is well correlated with the North Pacific index of Trenberth and Hurrell (1994).

Figure A1a shows the comparison of anomaly time series of the above-mentioned four EAWM indices. Also shown in Fig. A1b are DJF wind speed time series at three KMA meteorological stations (Inchon, Ullung, Cheju) bordering, respectively, each of the three 
TABLE A1. Correlation coefficients of different EAWM indices and other climate indices with winter surface variables in the East Asian marginal seas region during 1970-2005. Other comments are the same as in Table 1.

\begin{tabular}{|c|c|c|c|c|c|c|c|c|c|c|}
\hline & \multicolumn{4}{|c|}{ EAWM indices } & \multicolumn{6}{|c|}{ Other climate indices } \\
\hline & Park & JMA & Juhn & $\mathrm{Wu}$ & $\mathrm{SH}$ & WP & PDO & $\mathrm{AL}$ & $\mathrm{AO}$ & $\mathrm{SO}$ \\
\hline Wind & 0.88 & 0.64 & 0.34 & 0.69 & 0.87 & -0.52 & -0.07 & 0.05 & -0.26 & 0.11 \\
\hline$T_{\mathrm{atm}}$ & -0.87 & -0.84 & -0.78 & -0.84 & -0.81 & 0.69 & -0.23 & 0.24 & 0.48 & -0.20 \\
\hline SST & -0.79 & -0.62 & -0.48 & -0.73 & -0.77 & 0.55 & -0.18 & 0.08 & 0.38 & -0.15 \\
\hline $\mid$ Mean $\mid$ & 0.85 & 0.70 & 0.54 & 0.75 & 0.82 & 0.59 & 0.16 & 0.12 & 0.37 & 0.15 \\
\hline Rank & 1 & 4 & 6 & 3 & 2 & 5 & 8 & 10 & 7 & 9 \\
\hline
\end{tabular}

marginal seas (Yellow Sea, JES, and East China Sea), which are thus believed to represent winter wind speed variations over Korea and the surrounding marginal seas. The most remarkable is that while interannual variations are quite similar among these four indices, especially during the first two decades, there appears since the early 1990s to be a substantial divergence in decadal or longer-term variability due to differing degrees of the

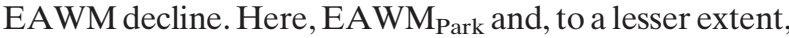
EAWM $_{\mathrm{Wu}}$ reveal the most abrupt decline from the mid1980s to the late 1990s, which is in good agreement with a steady decrease in wind speed over Korea by $25 \%-$ $30 \%$ between 1980 and 2000. Although all three KMA stations reveal a similar abrupt weakening trend, the wind speed at Cheju stands out as being most representative of the EAWM on both interannual and decadal time scales, probably thanks to the unobstructed environmental conditions open to the Cheju Channel of this particular island station, while the interannual wind variations at two other stations are relatively poorly correlated with the EAWM, for unknown reasons. The abrupt recent weakening of winter winds over Korea is consistent with a similar decrease $(28 \%)$ in monsoon winds over China in recent decades (Xu et al. 2006). In contrast, EAWM JMA $_{\text {A }}$ shows a relatively weak decline of the EAWM, whereas no significant decline appears in the EAWM Jhun $_{\text {time series, in conflict with the direct }}$ observations of winter monsoon winds over Korea and China. Our validation of the EAWM intensity is not exhaustive; however, there is supporting evidence from Korean colleagues (E. J. Kim et al. 2011, personal communication) who observed negative or near-neutral trends in winter wind speed for $1980-2000$ at $79 \%$ of a total of 98 stations they examined along the west coast of Japan and the east coast of Korea.

For a more quantitative validation of the above EAWM indices, Table A1 presents their correlation coefficients for the period of 1970-2005 with three kinds of wintertime surface variables (wind speed, air temperature, SST) observed over Korea and the East Asian marginal seas. To test the significance of the results, we calculated for each pair of correlating variables the effective degrees of freedom, $N^{*}$, according to the method using the normalized autocovariance function detailed in Emery and Thomson (1997). The resulting $N^{*}$ values were then used with standard tables to find the $95 \%$ significant levels of the correlations. For the sake of completeness, the correlations of other climate indices with the same surface variables are also given. For the wind speed, we used the DJF KMA data at Cheju, which best represent the intensity of the EAWM in our study area because of the favorable geographical location of this island station found in the midst of the central stream of northerly monsoon flow (see Fig. 2). For the air temperature, we used the DJF KMA data averaged over the seven selected stations over Korea previously prepared by Lee (2009). For the SST, we used the ERSST-derived JFM SST anomalies averaged over the western boundary region $\left(30^{\circ}-40^{\circ} \mathrm{N}, 120^{\circ}-140^{\circ} \mathrm{E}\right)$, covering most of the marginal seas.

Table A1 indicates that all EAWM indices correlate significantly with the wintertime surface variables of the western boundary region, although the degree of relationship varies significantly among indices. Of these, our new index, EAWM $M_{\text {Park }}$, shows the best performance, explaining $72 \%$ of the variance, on average, which is followed by $\mathrm{EAWM}_{\mathrm{Wu}}(56 \%)$ and $\mathrm{EAWM}_{\mathrm{JMA}}(50 \%)$. As expected from its absence of decline, EAWM $\mathrm{E}_{\text {Jhun }}$ shows the worst relationship (explaining $\sim 30 \%$ of the variance, on average) especially with wind speed and SST, although it is relatively well correlated with air temperature.

It is also interesting to note that SHI better correlates with the surface variables than any other EAWM indices except for $\mathrm{EAWM}_{\text {Park }}$, although the difference between $\mathrm{EAWM}_{\text {Park }}$ and SHI is not significant. Also, the WP (AO) index correlates significantly (marginally) at 0.59 (0.37) with the surface variables, while no significant correlations are observed with the PDO, AL, and SO indices. It is clear from this comparative analysis that the EAWM intensity is best represented by $\mathrm{EAWM}_{\text {Park }}$ (or near equivalently by SHI). The observed abrupt decline of the EAWM in recent decades is due mostly to the concomitant weakening of the SH, as SLP anomalies 


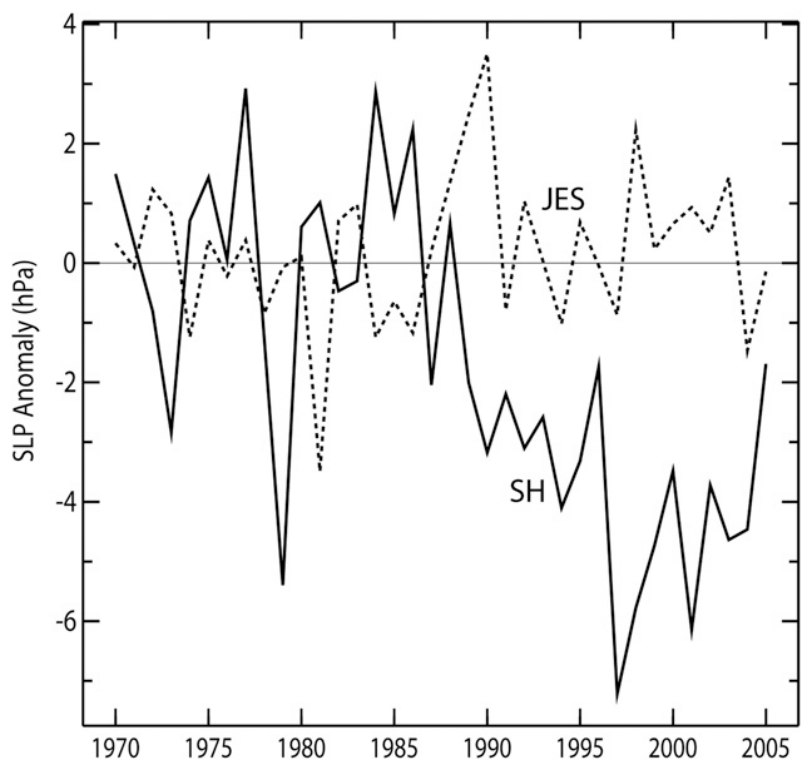

FIG. A2. Winter (DJF) SLP anomaly time series in the central region of the SH (solid) as compared with those of the JES center (dotted).

at the JES center reveal only a minor variability compared to a continuous drop by as much as $10 \mathrm{hPa}$ from 1984 to 1997 in the SH central region (Fig. A2).

\section{REFERENCES}

Barnston, A. G., and R. E. Livezey, 1987: Classification, seasonality and persistence of low-frequency atmospheric circulation patterns. Mon. Wea. Rev., 115, 1083-1126.

Cayan, D. R., 1992: Latent and sensible heat flux anomalies over the northern oceans: Driving the sea surface temperature. J. Phys. Oceanogr., 22, 859-881.

Chang, C.-P., Z. Wang, and H. Hendon, 2006: The Asian winter monsoon. The Asian Monsoon, B. Wang, Ed., Springer-Praxis, 89-127.

D'Arrigo, R., G. Jacoby, R. Wilson, and F. Panagiotopoulos, 2005: A reconstructed Siberian high index since A.D. 1599 from Eurasian and North American tree rings. Geophys. Res. Lett., 32, L05705, doi:10.1029/2004GL022271.

Deser, C., M. A. Alexander, and M. Timlin, 1999: Evidence for a wind-driven intensification of the Kuroshio Current Extension from the 1970s to the 1980s. J. Climate, 12, 1697-1706.

Emery, W. J., and R. E. Thomson, 1997: Data Analysis Methods in Physical Oceanography. Pergamon, $638 \mathrm{pp}$.

Gong, D.-Y., and C.-H. Ho, 2002: The Siberian high and climate change over middle to high latitude Asia. Theor. Appl. Climatol., 72, 1-9.

Gordon, A. L., and C. F. Giulivi, 2004: Pacific decadal oscillation and sea level in the Japan/East Sea. Deep-Sea Res. I, 51, 653663.

Hori, M. E., and H. Ueda, 2006: Impact of global warming on the eastern Asian winter monsoon as revealed by nine coupled atmosphere-ocean GCMs. Geophys. Res. Lett., 33, L03713, doi:10.1029/2005GL024961.
Jhun, J. G., and E. J. Lee, 2004: A new East Asian winter monsoon index and associated characteristics of the winter monsoon. J. Climate, 17, 711-726.

Kalnay, E., and Coauthors, 1996: The NCEP/NCAR 40-Year Reanalysis Project. Bull. Amer. Meteor. Soc., 77, 437-471.

Kawai, Y., T. Doi, H. Tomita, and H. Sasaki, 2008: Decadal-scale changes in meridional heat transport across $24^{\circ} \mathrm{N}$ in the Pacific Ocean. J. Geophys. Res., 113, C08021, doi:10.1029/ 2007JC004525.

Kelly, K. A., 2004: The relationship between oceanic heat transport and surface fluxes in the western North Pacific: 1970-2000. J. Climate, 17, 573-588.

Lee, B., 2009: Teleconnections associated with climate variability in Europe and Asia. Ph.D. thesis, Muséum National d'Histoire Naturelle, 229 pp.

Mantua, J. N., S. R. Hare, Y. Zhang, J. M. Wallace, and R. C. Francis, 1997: A Pacific interdecadal climate oscillation with impacts on salmon production. Bull. Amer. Meteor. Soc., 78, 1069-1080.

Miller, A. J., F. Chai, S. Chiba, J. R. Moisan, and D. J. Neilson, 2004: Decadal-scale climate and ecosystem interactions in the North Pacific Ocean. J. Oceanogr., 60, 163-188.

Minobe, S., A. Sako, and M. Nakamura, 2004: Interannual to interdecadal variability in the Japan Sea based on a new gridded upper water temperature dataset. J. Phys. Oceanogr., 34, 2382-2397.

Panagiotopoulos, F., M. Shahgedanova, A. Hannachi, and D. Stephenson, 2005: Observed trends and teleconnections of the Siberian high: A recently declining center of action. J. Climate, 18, 1411-1422.

Park, W. S., and I. S. Oh, 2000: Interannual and interdecadal variations of sea surface temperature in the East Asian Marginal Seas. Prog. Oceanogr., 46, 191-204.

Qiu, B., 2000: Interannual variability of the Kuroshio Extension and its impact on the wintertime SST field. J. Phys. Oceanogr., 30, 1486-1502.

_ 2002: Large-scale variability in the midlatitude subtropical and subpolar North Pacific Ocean: Observations and causes. J. Phys. Oceanogr., 32, 353-375.

_ 2003: Kuroshio Extension variability and forcing of the Pacific decadal oscillations: Responses and potential feedback. J. Phys. Oceanogr., 33, 2465-2482.

— Kuroshio Extension region. J. Phys. Oceanogr., 23, 2027 2041.

_ - and S. Chen, 2005: Variability of the Kuroshio Extension jet, recirculation gyre, and mesoscale eddies on decadal timescales. J. Phys. Oceanogr., 35, 2090-2103.

Rio, M.-H., and F. Hernandez, 2004: A mean dynamic topography computed over the World Ocean from altimetry, in-situ measurements and a geoid model. J. Geophys. Res., 109, C12032, doi:10.1029/2003JC002226.

Schneider, N., and A. J. Miller, 2001: Predicting western North Pacific Ocean climate. J. Climate, 14, 3997-4002.

,$- \ldots$, and D. W. Pierce, 2002: Anatomy of North Pacific decadal variability. J. Climate, 15, 586-605.

Seager, R., Y. Kushner, N. H. Naik, M. A. Cane, and J. Miller, 2001: Wind-driven shifts in the latitude of the Kuroshio-Oyashio Extension and generation of SST anomalies on decadal timescales. J. Climate, 14, 4249-4265.

Senjyu, T., M. Matsuyama, and N. Matsubara, 1999: Interannual and decadal sea-level variations along the Japanese coast. J. Oceanogr., 55, 619-633. 
Smith, T. M., and R. W. Reynolds, 2005: A global merged land-airsea surface temperature reconstruction base on the historical observations (1880-1997). J. Climate, 18, 2021-2035.

Solomon, S., D. Qin, M. Manning, M. Marquis, K. Averyt, M. M. B. Tignor, H. L. Miller Jr., and Z. Chen, Eds., 2007: Climate Change 2007: The Physical Science Basis. Cambridge University Press, 996 pp.

Sugimoto, S., and K. Hanawa, 2009: Decadal and interdecadal variations of the Aleutian low activity and their relation to upper ocean variations over the North Pacific. J. Meteor. Soc. Japan, 87, 601-614.

Takaya, K., and H. Nakamura, 2005: Mechanisms of intraseasonal amplification of the cold Siberian high. J. Atmos. Sci., 62, 4423-4440.

Tian, Y., H. Kidokoro, and T. Watanabe, 2006: Long-term changes in the fish community structure from the Tsushima warm current region of the Japan/East Sea with an emphasis on the impacts of fishing and climate regime shift over the last four decades. Prog. Oceanogr., 68, 217-237.

Trenberth, K. E., and D. A. Paolino, 1980: The Northern Hemisphere sea level pressure data set: Trends, errors, and discontinuities. Mon. Wea. Rev., 108, 855-872.

— tion in the Pacific. Climate Dyn., 9, 303-319.

Vivier, F., K. A. Kelly, and L. Thompson, 2002: Heat budget in the Kuroshio Extension region. J. Phys. Oceanogr., 32, 3436-3454.

Wallace, J. M., and D. S. Gutzler, 1981: Teleconnections in geopotential height field during the Northern Hemisphere winter. Mon. Wea. Rev., 109, 784-812.
Wang, L., and W. Chen, 2010: How well do existing indices measure the strength of the East Asian winter monsoon? Adv. Atmos. Sci., 27, 855-870, doi:10.1007/s00376-009-9094-3.

, W. Zhou, J. C. L. Chan, D. Barriopedro, and R. Huang, 2010: Effect of the climate shift around mid 1970s on the relationship between wintertime Ural blocking circulation and East Asian climate. Int. J. Climatol., 30, 153-158.

Watanabe, T., K. Hanawa, and Y. Toba, 1987: Analysis of year-toyear variation of water temperature along the coast of the Japan Sea. Prog. Oceanogr., 17, 337-357.

Wu, B. Y., and J. Wang, 2002: Winter Arctic Oscillation, Siberian High and East Asian winter monsoon. Geophys. Res. Lett., 29, 1897, doi:10.1029/2002GL015373.

Xu, M., C.-P. Chang, C. Fu, Y. Qi, A. Robock, D. Robinson, and H. Zhang, 2006: Steady decline of East Asian monsoon winds, 1969-2000: Evidence from direct ground measurements of wind speed. J. Geophys. Res., 111, D24111, doi:10.1029/ 2006JD007337.

Yasuda, T., and K. Hanawa, 1999: Composite analysis of North Pacific subtropical mode water properties with respect to the strength of the wintertime East Asian monsoon. J. Oceanogr., 55, 531-541.

Youn, Y.-H., 2005: The climate variabilities of air temperature around the Korean Peninsula. Adv. Atmos. Sci., 22, 575-584.

Yu, L., 2007: Global variations in oceanic evaporation (1958-2005): The role of the changing wind speed. J. Climate, 20, 5376-5390. , and R. A. Weller, 2007: Objectively analyzed air-sea heat fluxes for the ice-free global oceans (1981-2005). Bull. Amer. Meteor. Soc., 88, 527-539. 